\title{
Driving Factors of Carbon Dioxide Emissions and the Impact from Kyoto Protocol
}

\author{
Nicole Grunewald \\ Inmaculada Martínez-Zarzoso
}

\author{
CESIFO WORKING PAPER NO. 2758 \\ CATEGORY 10: ENERGY AND CLIMATE ECONOMICS
}

August 2009

Presented At CESifo Venice Summer Institute, July 2009
An electronic version of the paper may be downloaded
- from the SSRN website:
www.SSRN.com
- from the RePEc website:
www.RePEc.org
- from the CESifo website:
www.CESifo-group.org/wp 


\title{
Driving Factors of Carbon Dioxide Emissions and the Impact from Kyoto Protocol
}

\begin{abstract}
In the last two decades increasing attention has been paid to the relationship between environmental degradation and economic development. According to the Environmental Kuznets Curve (EKC) hypothesis this relationship may be described by an inverted-U curve. However, recent evidence rejects the EKC hypothesis for GHG emissions in a broad sense. In this paper we aim to investigate whether the EKC behavior for $\mathrm{CO} 2$ emissions could be proved on the behalf of institutional regulations. We analyze the driving factors of $\mathrm{CO} 2$ for developed and developing countries to test the theory of the EKC in the context of environmental regulations using a static and dynamic panel data model. We consider the Kyoto Protocol and the Clean Development Mechanism (CDM). The results from this study indicate that the Kyoto obligations have a reducing effect on $\mathrm{CO} 2$ emissions in developed and developing countries.
\end{abstract}

JEL Code: Q54, Q56.

Keywords: environmental Kuznets Curve, Kyoto Protocol, CDM.

Nicole Grunewald

Department of Economics

University of Goettingen

Platz der Göttinger Sieben 3

37073 Göttingen

Germany

ngrunew@uni-goettingen.de
Inmaculada Martínez-Zarzoso

International Economics Institute

University Jaume I

Spain-Castellón

martinei@eco.uji.es

The paper was presented at the CESifo Venice Summer Institute 2009. 


\section{Driving Factors of Carbon Dioxide Emissions and the Impact from Kyoto Protocol}

\section{Introduction}

The EKC Hypothesis describes the relationship between economic growth in terms of per capita income and environmental degradation. There is a supposed inverse U-shaped relationship between per capita income and environmental degradation. The hypothesis states that with increasing income per capita, environmental degradation first rises and after reaching a maximum level of degradation, the turning point, it starts to decline (Figure 1).

Figure 1 Shape of the Environmental Kuznets Curve

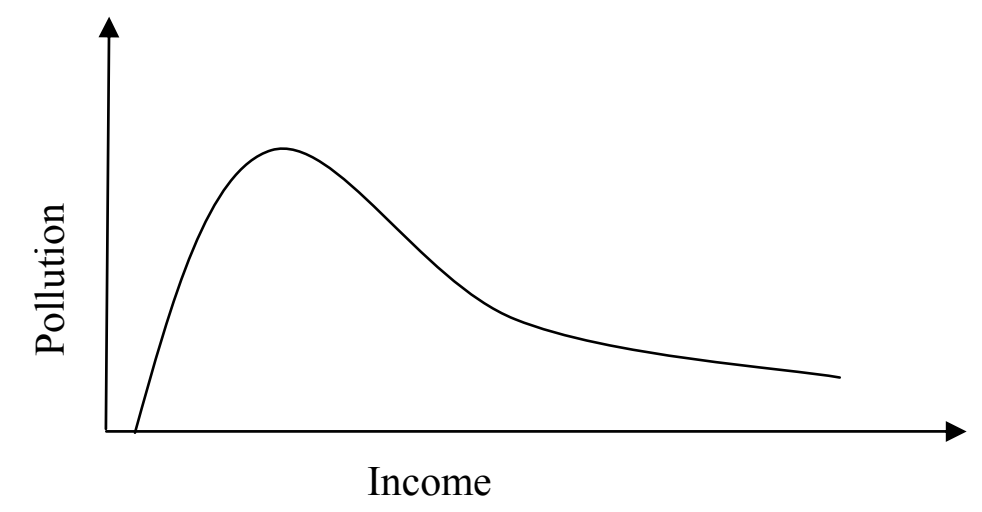

Source: Lieb (2003, p.2)

Grossman and Krueger (1995), Holtz-Eakin and Selden (1995) as well as Selden and Song (1994) were some of the first to find this relationship, which was derived from the work of Kuznets (1955) on economic growth and income inequality. Kuznets (1955) found that global economic growth will enter a phase of declining inequality after passing through a period of rising income inequality. Therefore economic growth appeared to be the solution of increasing income inequalities and gave hope to a more equal future without applying any redistributional measures. By transferring these findings from Kuznets it was assumed that rising income will lead to declining levels of environmental degradation. Beckerman (1992) argues that economic growth could lead to improvements in environmental degradation in the long run. He received heavy critique to make economic growth appear to be the panacea for the threats, which used to be related with the term "Globalization". Economic growth and globalization where linked with the exploitation of developing countries and natural resources 
as well as increasing environmental degradation. With the Kuznets Hypothesizes it seemed possible to actually promote economic growth as a tool for a more equal distribution of income or a decreasing level of environmental degradation.

There have been many studies analyzing the relationship between income growth and $\mathrm{CO}_{2}$ emissions. ${ }^{2}$ We test this relationship again since international climate agreements such as the Kyoto Protocol aim to reduce emissions without jeopardizing economic growth. The paper is structured as follows. International climate policy is briefly described in Section 2. Section 3 discuses the measurement and sources of the data used and presents the empirical analysis and main findings. Finally, the concluding remarks can be found in Section 4.

\section{International Climate Policy}

\subsection{The Framework Convention on Climate Change}

When we talk about the international environmental regime we cannot refer to one centralized general authority. Dutt (2009, p.12) describes it as "a set of mechanisms and institutions that govern environmental outcomes on an international level". Those institutions consist of international governmental organizations, national governments, research or private institutions and non profit as well as nongovernmental organizations. Dutt (2009) divides the body of international law into hard and soft law. Hard law refers to international treaties and formal binding agreements that have been ratified, such as the Kyoto or the Montreal Protocol. Soft law refers to non binding agreements or guidelines, which rather inhibit an advising character than an enforcing one like the Rio Declaration.

The Rio Declaration followed the UN Conference on Environment and Development, the so called Earth Summit in Rio de Janeiro in 1992. At the conference, which is considered to be the starting point of mayor international interest on environment and development, the UN Framework Convention on Climate Change (UNFCCC) was founded. From the Rio Conference until the UN World Summit on Sustainable Development in Johannesburg in 2002 the term sustainable development received more and more attention. Sustainable development was defined by the Brundtland Report as "development that meets the needs of the present without compromising the ability of future generations to meet their own needs"

\footnotetext{
${ }^{2}$ For a summary of earlier investigations refer to Appendix 1.
} 
UNWCED (1987, p.46). In the report from the Commission on Our Common Future, which was chaired by the Norwegian prime minister Gro Harlem Brundtland, environmental degradation and poverty alleviation were for the first time treated as joint problem. Nevertheless, we will concentrate less on sustainability in terms of stable consumption levels for future generations and focus on a more equal distribution of consumption, hence poverty reduction.

Fuhr et al. (2008), Schubert et al. (2007) and Swinton and Sarkar (2007) treat the question if environmental policy can be sustainable and poverty reducing. They analyze the possible potential of CDM from the Kyoto Protocol to be poverty reducing. On Average developing countries will suffer more from climate change in terms of extreme weather, floods or rising sea levels and the related losses in the agricultural sector. Since they are more vulnerable, there is the need that they should get special protection as well. The "polluter pays principle" seems appropriate since the majority of the nowadays developed countries caused many of today's environmental problems to a big extend on their own. A contradictive problem occurs since soon some of the developing countries will enter a stage in the industrialization process, during which they will pollute as much or even more as the developed countries during the past. The task is to integrate fast growing countries like China into international environmental policy regulations without jeopardizing their future growth opportunities by putting obligations on them. However, without giving them a free ride to pollute as much as they want, meanwhile the developed countries carry the burden on reducing pollution. This problem is treated under the "common but differentiated responsibilities" of Kyoto Protocol.

Schubert et al. (2007) consider that poverty reduction should include a save access to drinking water, food and medical supply as well as good institutions and a reasonable level of education or property rights as well as reforms. Panayotou (1997) proves that growth is the more environmental beneficial, the better the institutions of a country are. He finds an EKC for $\mathrm{SO}_{2}$, and that better institutions lead to a more equal income distribution. So the focal point is driven away from just growth as the panacea for the developing countries' environment and is now but on poverty reducing growth. The question is whether we can achieve that from international environmental agreements. Therefore we will have a closer look on the Kyoto Protocol. 


\subsection{Kyoto Protocol and CDM}

The Kyoto Protocol was prepared by the annual meetings of the UNFCCC and adopted for use at the 1997 meeting in Kyoto. The protocol divides the member countries into different groups: Annex-B with GHG emissions reduction obligations and the Non-Annex-B without emission reduction obligations. It covers the main GHGs such as $\mathrm{CO}_{2}$, which represents the biggest share, and five other GHGs. The goal of the protocol is a reduction of GHGs by $5.3 \%$ until 2012 compared to the countries $\mathrm{CO}_{2}$ emission levels in 1990. It finally entered into force in 2005 after Russia had ratified the treaty and therewith at least 55 countries, which emit at least $55 \%$ of the global GHG emissions, had ratified the treaty.

The reason for the long delay between the adoption and the entering into force of the protocol was mainly due to the question which countries should have binding emission reduction obligations and what are the estimated costs from these obligations. Further there was the question of how to incorporate and support developing countries, which in 1997 did not account for a big share in emissions but soon will, like in the case of China which faced strong increases in its emissions during recent years.

Figure 2 Changes in $\mathrm{CO}_{2}$ Emission among Countries grouped by Income

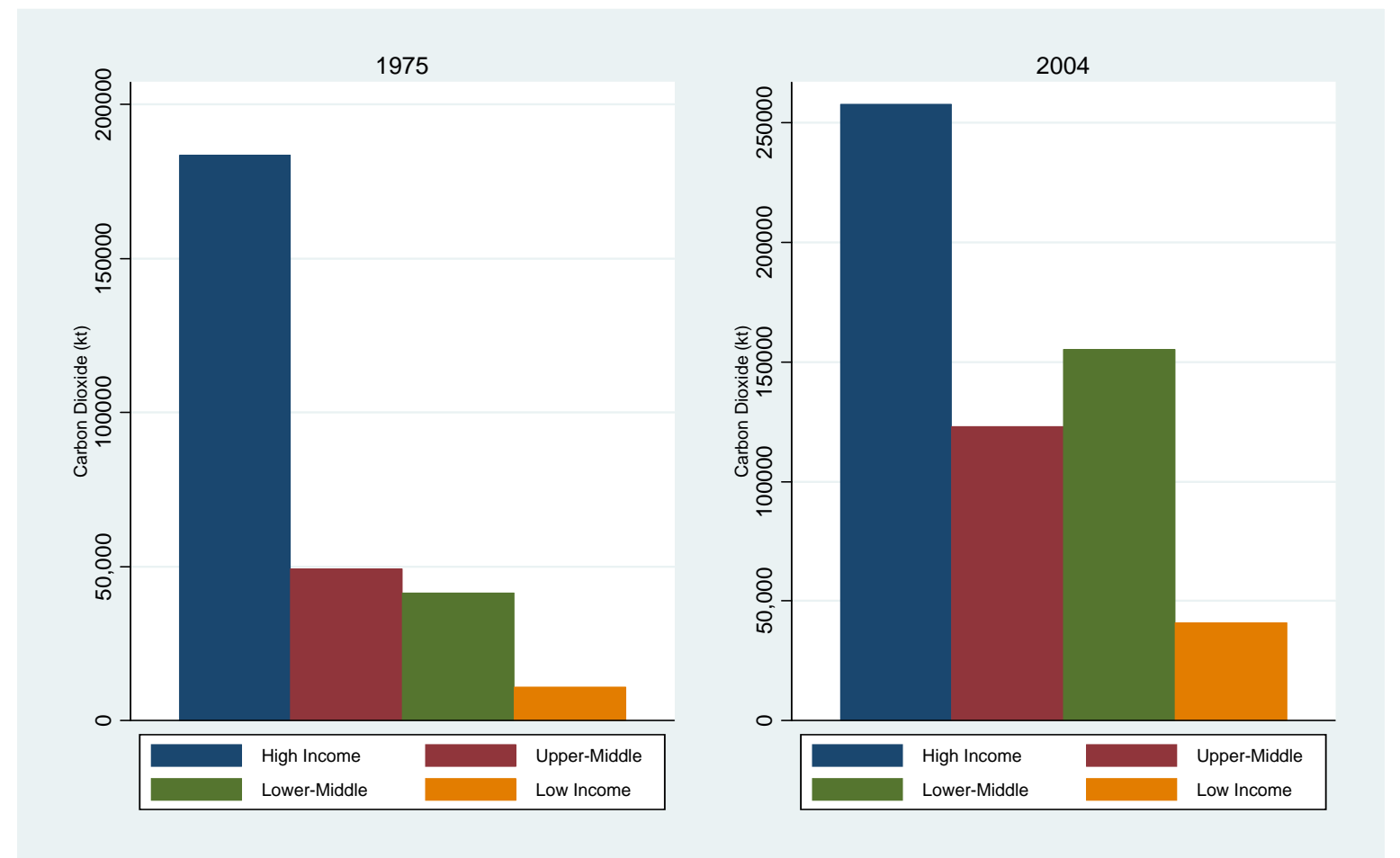

Source: Author's elaboration 
Figure 2 shows the overall growth in absolute emissions among countries grouped by income. It shows that the share in $\mathrm{CO}_{2}$ emissions from middle and low income countries has risen considerably between 1975 and 2004. As many of those countries are in the stage of industrialization we expect this trend to continue. To overcome the difficulty of how to integrate developing countries, the Kyoto Protocol tries to enhance sustainable development among developing countries via its flexible mechanisms, such as the CDM.

The CDM opens the possibility to fulfill a country's GHG emission reduction obligations with Certified Emission Reduction Units (CERs) from any other developing country which is a member of the UNFCCC. It could be considered a back door for the developed countries to get cheap CERs and therewith fulfill their obligations at low costs, or even to promote sustainable development. The CDM aims on four goals: First of all, it shall integrate developing countries in the international framework on environmental regulations by not putting any costly obligations on those countries. Second, the mechanism opens new markets to those countries, or in other words integrates those countries in a new market, such as the international carbon market, which trades the CERs created from CDM. Third, The CDM could be a tool to provide sustainable development among poorer countries. Finally, and probably the most criticized but also reasonable goal is, that emissions are reduced at lowest cost. The technology applied in developed countries might be at a much higher level of energy efficiency, than the technology applied in developing countries. Therefore, it might be possible to e.g. reduce with the same amount of money invested five times more GHG in China than in Germany.

The cost efficiency concept has to be evaluated. It does not necessarily go in line with sustainability or poverty reduction. Ellis (2007), Liu (2008) and Schubert et al. (2007) conclude that the decision for investing in a CDM project is rather driven by the amount of CERs gained, than by sustainability gains from the positive side effects of the projects in the implementing countries. The distribution of the projects shows that they are mainly located in fast growing developing economies such as China, India and Brazil. In Africa, where the investors face lower gains and higher risks, fewer projects are located.

There are further critical aspects towards the CDM. Liu (2008) states, that if developing countries sell their "low cost" reduced emissions now, they might have to face very costly emission reductions when they will join the protocol with their own reduction obligations in the near future. This argument could be called a sale of emission reductions. Liu (2008) therefore claims that the projects should be evaluated by their type and therefore by their 
potential sustainability. Another important issue is the amount of reduced emissions from $\mathrm{CDM}$ on the international carbon market. A supply surplus of CERs might lead again to another decline in the prices for CERs which would drive investors away from the CDM projects since revenues are expected to be low. Hence, we would not achieve a long term integration of developing countries.

Ellis (2007) states that a price of \$3-6 per CER unit will not create enough market pull to attract investors for capital intensive projects. Unfortunately the projects with the lower revenues tend to be more sustainable. Investing in CDM projects is still considered to be a risky venture. Lecocq and Ambrosi (2007) find that about $80 \%$ of the investors are private ones. They conclude that this money is additional to official development assistance. However, it remains doubtful whether it is additional to common foreign direct investment. Lecocq and Ambrosi (2007) point to another difficult issue of the CDM. Since the emission reductions from the projects have to be additional to the business as usual in the country's environmental policy plans, there is a strong incentive for the implementing country to not plan on passing any new environmental policy. In other words the CDM enhances counteractive environmental policies in developing countries, since the countries might apply for as many CDM projects as possible instead of making progress on their own.

Swinton and Sarkar (2007) analyze costs and benefits for developing countries from Kyoto Protocol. They draw a very optimistically perspective. First of all developing countries are integrated in international markets and even exhibit a comparative advantage, since they can reduce GHG emissions at a lower unit cost. Further, they can attract foreign capital, which will create positive side effects and will lead them on a cleaner path during growth. Last but not least the integration in international environmental law may lead to an improvement in the developing countries institutions, which again will cause positive side effects. On average countries with good institution grow faster. Rose and Spiegel (2008) test engagement in noneconomic agreements to be growth enhancing and find that joint environmental interests do foster economic ties. They find evidence that non-participation may lead to costs in terms of lower economic exchange in international trade and foreign direct investment. Fuhr et al. (2008) point to the positive effect of integrating the private sector via CDM into international environmental regulations. The private sector seems to perform better when it comes to the realization of $\mathrm{CDM}$ projects, which might be due to lower administrative efforts. The arguments in favor for the $\mathrm{CDM}$ focus on the aspect of its integrative character and that, $\mathrm{GHG}$ emissions are reduced at the place of lowest cost. Schneider et al. (2008) prove the potential 
of technology transfer through the CDM. This seems reasonable since so far most of the projects implemented are in the energy sector as displayed in Figure 3. The reason behind it is that there are large amounts of emissions to be reduced at a moderate risk level.

\section{Figure 3 Types of Registered CDM Projects}

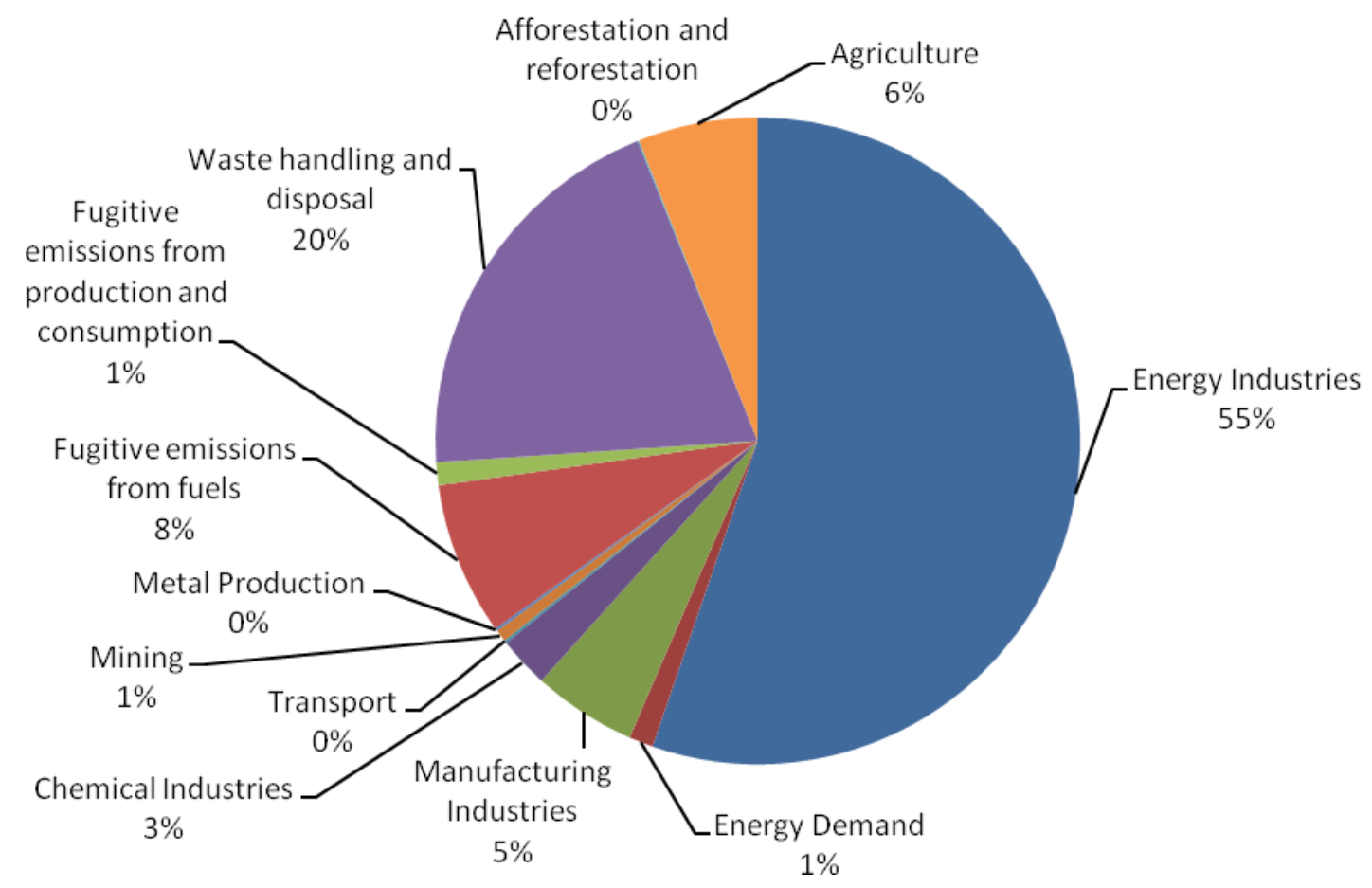

Source: UNFCCC (2008)

Most of the CDM projects are large scale projects. We could speak of sustainable projects, if they help to preserve resources for future generations. And we could consider projects to be absolute poverty reducing, if the increase in the quality of life of the poorest is stronger, than the increase in the quality of life of the richest people living in a country. In developing countries poor classes are many times stronger exposed to environmental problems than rich ones. They suffer more from infrastructure deficits and bad waste management. Very often they have only limited access to drinking water or are undersupplied with electricity. CDM projects contributing to relieve those problems could be considered poverty reducing.

\section{Study on $\mathrm{CO}_{2}$ Emissions}

In this section we will estimate a model to shed light on the question if there does exist an EKC for $\mathrm{CO}_{2}$ and if Kyoto Protocol has an impact on $\mathrm{CO}_{2}$ emissions. A modified version of the stochastically impact population affluence technology model (STRIPAT) as used by Cole 
and Neumeyer (2004), Dietz and Rosa (1997), Martínez-Zarzoso (2008), Martínez-Zarzoso et al. (2007), Shi (2003) and York et al. (2003) will be estimated. We subdivide the countries into four groups by GDP to highlight the different driving forces of $\mathrm{CO}_{2}$ emissions among them. By grouping the countries we also make them more homogenous, which contributes positively to the quality of our pooled econometric models. We will start the analysis with a static regression model and then compare those results to a dynamic model.

\subsection{Methodology and Data}

Dietz and Rosa (1997) analyze the driving forces of $\mathrm{CO}_{2}$ emissions. They consider the rise in $\mathrm{CO}_{2}$ emissions to be mainly caused by human activities and apply an environmental impact model IPAT, which was developed by Ehrlich and Holdren (1970). Dietz and Rosa (1997) divide human activities into four anthropogenic forces, which they consider to be the main driving forces behind the rise in $\mathrm{CO}_{2}$ emissions. The first one is population (P) itself. The second is economic activity, which is referred to as affluence (A) in the model and which is measured in GDP per capita. The third is technology (T) which describes the technical standard of production and is measured in energy efficiency or industrial activity. Further determinants of $\mathrm{CO}_{2}$ are political and economic institutions as well as attitudes and beliefs.

$I=P+A+T$

where the variable $I$ is the environmental impact.

The IPAT model can be applied on every human driven environmental impact, not only $\mathrm{CO}_{2}$ emissions. The main shortcoming of the model is that it cannot account for non-monotonic or non-proportional effects from the variables since it is an accounting equation. To overcome this shortcoming Dietz and Rosa (1997) reformulated the model into a stochastic equation, which can be used for empirical hypothesis testing. The specification of their STRIPAT model is as follows:

$I_{i}=\alpha P_{i}^{\beta} A_{i}^{\gamma} T_{i}^{\delta} \varepsilon_{i}$

where the constant is represented by $\alpha$, the parameters $\beta, \gamma$ and $\delta$ are the coefficients which will be estimated by the model. The error term, which represents all the unexplained variance of the model, is denoted by $\varepsilon$. Finally, $i$ stands for countries and indicates that the quantities of $A, P, T$ and $\varepsilon$ vary across countries. 
Dietz and Rosa (1997) included $T$ in the error term and did not separately estimate the influence of technology on emissions, whereas York et al. (2003) extended the model and introduced $\mathrm{T}$ as another explanatory variable. By taking natural logarithms $(\ln )$ from both sides of equation 2 , we obtain

$\ln I_{i}=\alpha_{0}+\beta \ln P_{i}+\gamma \ln A_{i}+\delta \ln T_{i}+\mu_{i}$

where $\alpha_{0}=\ln \alpha$ and $\mu_{i}=\ln \varepsilon_{i}$.

York et al. (2003) also investigated the introduction of further variables such as variables for institutions and squared variables to measure nonlinearities in the model. They therefore laid the foundation for the specification of the model, which we applied

$$
\begin{aligned}
& \ln C O_{2 i t}=\alpha_{i}+\lambda_{t}+\beta_{1} \ln P_{i t}+\beta_{2} \ln G D P_{i t}+\beta_{3} \ln G D P_{i t}^{2}+\beta_{4} \ln I A_{i t}+\beta_{5} K y o t o O b+\beta_{6} C D M \\
& +\beta_{7} E I T+v_{i t}
\end{aligned}
$$

The dependent variable in our model is $\mathrm{CO}_{2}$ Emissions measured in kilo tons. $\alpha_{i}$ and $\lambda_{t}$ are country and year specific effects, which are used to control for unobservable countryheterogeneity and for common time-varying effects that could affect emissions. Population (Pop) is measured in number of inhabitants. We follow here the approach of Cramer (1998) and Cramer and Cheney (2000), who were some of the first to test whether the elasticity of emissions with respect to population is unity. ${ }^{3}$ The next variables in our model, GDP per capita and GDP per capita squared, represent the corner stone of the analysis for the EKC. ${ }^{4}$ If the coefficient from GDP would result to be positive and therefore contribute to rising emissions and the squared term would become negative and therefore marking a possible turning point with declining levels of emissions, we observe an inverse U-shape of the pollution-income relationship. As a proxy for technological change we use industrial activity (IA), calculated by the share of the manufacturing industry in total GDP. ${ }^{5}$ We would assume countries which are mainly dominated by agricultural production facilities to exhibit a low

\footnotetext{
${ }^{3}$ In the classical approach it is assumed to be unity by using the logarithm of the pollutant in per capita terms.

${ }^{4}$ We always refer to GDP per capita when mentioning GDP.

${ }^{5}$ We also applied a different applications using energy efficiency as oil input per output in terms of GDP and the number registered patents as a proxy technological change. The results were neither convincing nor did they fit into the scheme of the IPAT model in the case of the later one.
} 
percentage and those who are in the stage of industrialization to exhibit a high percentage of manufactured goods in their GDP. Developed countries in contrary might show already a low percentage if they yet have reached the stage of specialization in service industries.

In order to measure the impact of the Kyoto Protocol on $\mathrm{CO}_{2}$ emissions we created two dummy variables: The first, Kyoto obligations (KyotoOb), takes the value of one, if a country has ratified the Kyoto Protocol and faces emissions reduction obligations from the treaty, otherwise it takes the value zero. The variable takes the value one from the year in which the country has ratified the Kyoto Protocol onwards. Most of the countries with emission reduction obligations ratified the protocol in 2002. The second dummy variable takes the value of one if the country has implemented any projects from the Kyoto Protocol's flexible mechanism the CDM. The CDM variable takes the value one if the country has implemented at least one CDM project during that year.

Finally we introduce a third dummy variable, which controls for the declining emissions from economies in transition (EIT). ${ }^{6}$ The UNFCCC $(1992,8)$ considers economies, which are "undergoing the process of transition to a market economy" as countries in transition. Those countries face a strong decline in emissions since 1992 due to the economic recession, which set in after the break down of the Council of Mutual Economic Assistance in 1991. The high amount of emission reductions from those countries is often referred to as "hot air" since the reductions were not created by emission mitigation efforts, but by economic slowdown. The dummy variable EIT takes the value one from 1992 on for all the countries considered economies in transition by the UNFCCC (1992).

We will investigate the driving forces behind $\mathrm{CO}_{2}$ emissions and will point out differences between developed countries and developing countries. We follow the approach of Shi (2003) and Martínez-Zarzoso (2008) and form four sub-groups of countries according to their GDP. The group of high income countries is classified by a Gross National Income (GNI) per capita, calculated using World Bank Atlas Method of $\$ 11,116$ or more. The upper-middle income group ranges from $\$ 3,596$ to $\$ 11,115$, the lower-middle income group from $\$ 906$ to $\$ 3,595$ and the low income group ranges from $\$ 0$ to $\$ 905$.

\footnotetext{
${ }^{6}$ For a list oft the economies in transition refer to Appendix 3.
} 
Figure 4 gives an overview on the development of $\mathrm{CO}_{2}$ emissions over time and shows that emissions are in general steadily increasing for the whole set of countries. The high and upper-middle income groups emit a much higher amount of $\mathrm{CO}_{2}$ and show a stronger volatility. The low income countries emitted in 2004 about one fifth of the amount the amount $\mathrm{CO}_{2}$ in kilo tons compared to the high income countries.

\section{Figure 4 Carbon Dioxide Emissions grouped by Income}
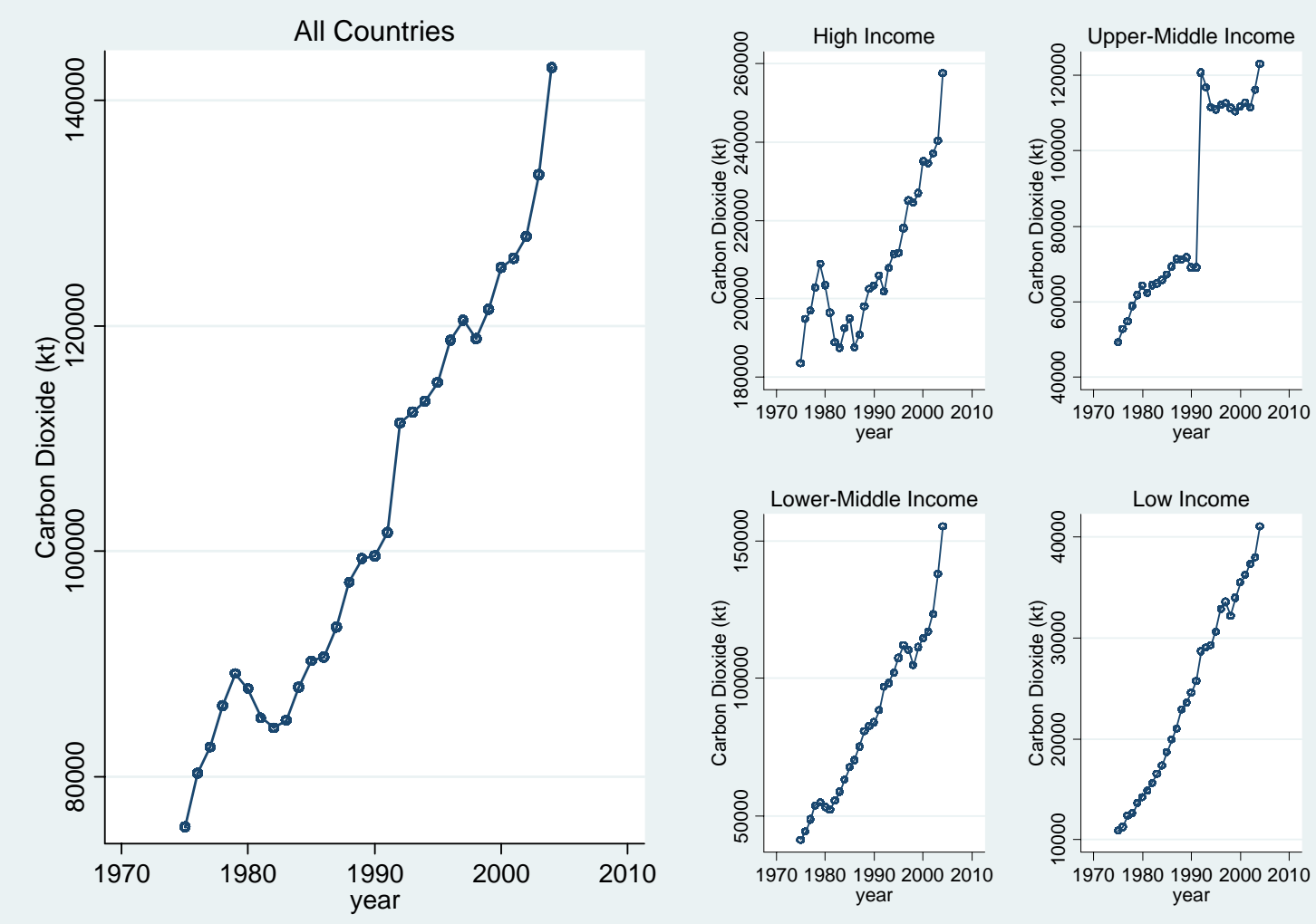

Source: Author's elaboration

The data are from the World Bank World Development Indicators (WDI) CD 2008 and cover a panel of 123 countries from 1975 until 2004. ${ }^{7}$ The panel is not balanced since e.g. the data on $\mathrm{CO}_{2}$ emissions for economies in transition are only available from 1992 onwards. The data on the ratification and the $\mathrm{CO}_{2}$ emission reduction obligations are from the UNFCCC (2008)

\footnotetext{
${ }^{7}$ In an earlier version of the model we obtained our data from the WDI 2007 and came to different results in the econometrical analysis. This difference is due to the fact that some of the earlier values for $\mathrm{CO}_{2}$ were revised for the WDI 2008.
}

For a list of all the countries refer to Appendix 2. 
and data on the number of implemented CDM projects by host country come from the UNEP Risoe Centre (2008).

\subsection{Econometrical Analysis and Results}

\subsubsection{Static Approach}

We first estimated a version of Equation (4) by ordinary least squares (OLS) assuming that there is not unobserved heterogeneity across countries $\left(\alpha_{i}=\alpha\right)$ and assuming also common slope coefficients $\beta$ for all countries. ${ }^{8}$

It is very likely that the estimated OLS coefficients are biased due to the existence of unobserved heterogeneity. Country specific effects $\left(\alpha_{\mathrm{i}}\right)$ could be used to model the unobserved heterogeneity between the observed countries. Since our panel consists of 123 countries which strongly vary in their size, wealth, geographical location or institutions this step seems reasonable. We take account for those effects by estimating a random effects (RE) regression and testing with the Lagrange Multiplier test for the significance of country specific effects. The outcome of the test yields that there are country specific effects to be taken into account. We therefore estimate a random effect model.

The RE error component model assumes the country specific effects $\alpha_{\mathrm{i}}$ are not correlated with the independent variables $x_{i t}$ (orthogonality condition), in other words $E\left(x_{i t} \alpha_{\mathrm{i}}\right)=0$. If those effects are correlated with the independent variables, the RE coefficients are inconsistent and only the fixed effects (FE) estimates are consistent. Therefore we test the orthogonality condition by applying the Mundlack approach and estimating an extended version of the RE model with the mean of all the independent variables added as explanatory variables. ${ }^{9}$ Since the estimated coefficient of the variable's means are different from zero but not significant, the coefficients of the RE regression are consistent. ${ }^{10}$ The RE regression uses all the variation between individual countries and over time. It uses therefore more information than the FE

\footnotetext{
${ }^{8}$ The results of the OLS regression are reported in Table 1 column 1.

${ }^{9}$ The results from the Mundlack approach are reported in table 1 column 4 .

${ }^{10}$ Only the average population has a positive and significant coefficient, however the coefficient of population in the RE model does not differ significantly from the coefficient of population in the FE model. We also applied the Hausman test to verify $E\left(x_{i t} \mu_{i}\right)=0$ but the Hausman test turns out to be not reliable in our model specification.
} 
estimator, which uses only the variation over time. The RE estimator treats the country specific effects as random. One might expect the country specific effects to be fixed. But, since we applied the Mundlack approach and the RE estimator is more efficient than the FE estimator, we will continue with the RE model. For completeness we also present the results obtained using the within estimator (FE model) in column 3 of Table 1.

\section{Table 1 Results from the Static Model}

\begin{tabular}{|c|c|c|c|c|c|c|}
\hline & OLS & $\mathbf{R E}$ & FE & RE & $\begin{array}{c}\text { FGLS } \\
\text { AR1 } \\
\end{array}$ & $\begin{array}{c}\text { FGLS } \\
\text { PSAR1, } \\
\text { Hetero } \\
\end{array}$ \\
\hline $\ln P o p$ & $\begin{array}{r}1.101 * * * \\
(163.94)\end{array}$ & $\begin{array}{r}1.041^{* * *} \\
(41.25)\end{array}$ & $\begin{array}{r}1.023 * * * \\
(4.97)\end{array}$ & $\begin{array}{r}1.065^{* * *} \\
(40.01)\end{array}$ & $\begin{array}{r}1.151^{* * *} \\
(10.29)\end{array}$ & $\begin{array}{r}1.321 * * * \\
(22.35)\end{array}$ \\
\hline InPop_m & & & & $\begin{array}{r}0.285 * * * \\
(4.55)\end{array}$ & & \\
\hline $\operatorname{lnGDP}$ & $\begin{array}{r}2.616 * * * \\
(17.67)\end{array}$ & $\begin{array}{r}1.003^{* * *} \\
(3.80)\end{array}$ & $\begin{array}{r}0.946^{*} \\
(1.75)\end{array}$ & $\begin{array}{r}0.934 * * * \\
(3.45)\end{array}$ & $\begin{array}{l}0.160 \\
(0.79)\end{array}$ & $\begin{array}{r}0.798 * * * \\
(5.67)\end{array}$ \\
\hline lnGDP_m & & & & $\begin{array}{l}0.114 \\
(1.11)\end{array}$ & & \\
\hline $\operatorname{lnGDP}^{2}$ & $\begin{array}{r}-0.081 * * * \\
(9.42)\end{array}$ & $\begin{array}{c}-0.002 \\
(0.15)\end{array}$ & $\begin{array}{l}-0.005 \\
(0.15)\end{array}$ & $\begin{array}{l}0.002 \\
(0.14)\end{array}$ & $\begin{array}{r}0.037 * * * \\
(2.84)\end{array}$ & $\begin{array}{r}-0.005 \\
(0.53)\end{array}$ \\
\hline $\ln I A$ & $\begin{array}{r}0.052 * * \\
(1.97)\end{array}$ & $\begin{array}{r}0.215^{* * *} \\
(8.89)\end{array}$ & $\begin{array}{r}0.217 * * * \\
(4.28)\end{array}$ & $\begin{array}{r}0.207 * * * \\
(8.53)\end{array}$ & $\begin{array}{r}0.109 * * * \\
(5.01)\end{array}$ & $\begin{array}{r}0.088 * * * \\
(7.23)\end{array}$ \\
\hline InIA_m & & & & $\begin{array}{r}-0.186 \\
(1.49)\end{array}$ & & \\
\hline KyotoOb & $\begin{array}{r}-0.399 * * * \\
(9.25)\end{array}$ & $\begin{array}{r}-0.153 * * * \\
(5.99)\end{array}$ & $\begin{array}{r}-0.145^{* * *} \\
(3.32)\end{array}$ & $\begin{array}{r}-0.147 \\
(6.14)\end{array}$ & $\begin{array}{r}-0.068^{* *} \\
(2.05)\end{array}$ & $\begin{array}{r}-0.022^{* * * *} \\
(2.98)\end{array}$ \\
\hline CDM & $\begin{array}{r}-0.182 * \\
(1.72)\end{array}$ & $\begin{array}{r}-0.007 \\
(0.17)\end{array}$ & $\begin{array}{l}0.005 \\
(0.09)\end{array}$ & $\begin{array}{l}0.018 \\
(0.41)\end{array}$ & $\begin{array}{l}0.013 \\
(0.31)\end{array}$ & $\begin{array}{l}0.010 \\
(0.79)\end{array}$ \\
\hline EIT & $\begin{array}{r}0.587 * * * \\
(13.27)\end{array}$ & $\begin{array}{l}0.101 \\
(1.12)\end{array}$ & $\begin{array}{r}-0.159 * * \\
(2.08)\end{array}$ & $\begin{array}{l}0.132 \\
(1.56)\end{array}$ & $\begin{array}{r}-0.070 \\
(0.77)\end{array}$ & $\begin{array}{r}-0.032 \\
(1.03)\end{array}$ \\
\hline $\begin{array}{l}\text { Time } \\
\text { Dummies } \\
\text { Country }\end{array}$ & no & yes & yes & No & yes & yes \\
\hline Dummies & no & no & no & No & yes & yes \\
\hline Constant & $\begin{array}{r}-24.433 * * * \\
(37.91)\end{array}$ & $\begin{array}{r}-16.068^{* * *} \\
(13.29)\end{array}$ & $\begin{array}{r}-15.164^{* * *} \\
(4.53)\end{array}$ & $\begin{array}{r}-20.937 * * * \\
(13.37)\end{array}$ & $\begin{array}{r}-12.287 * * * \\
(6.02)\end{array}$ & $\begin{array}{r}-17.772 * * * \\
(15.67)\end{array}$ \\
\hline $\begin{array}{l}\text { Observatio } \\
\text { ns }\end{array}$ & 3265 & 3265 & 3265 & 3265 & 3265 & 3265 \\
\hline R-squared & 0.93 & & 0.55 & & & \\
\hline Countries & & 170 & 170 & 170 & 170 & 170 \\
\hline
\end{tabular}

Note: $\mathrm{t}$-statistics are in brackets $* * *$ and $* * *$ denote significance at $10 \%, 5 \%$ and $1 \%$ level, respectively.

In Table 1 column 2 we show the results from the RE regression. The variable KyotoOb is negative and significant meanwhile the variable $C D M$ is not significant. Since most of the countries with emission reduction obligations ratified the Kyoto Protocol in 2002, we 
introduce interaction terms for the variable KyotoOb and the years 2002 and 2003, to see if there are year specific effects. Those interaction terms turned out be not significant and therefore are not reported. We also control for the strong decline in emissions from economies in transition by introducing the dummy variable EIT.

There are two further issues concerning the consistency of our results in column 2 of Table 1, which have not been addressed so far. One is heteroscedasticity in the error term, which refers to changes in their variance and could lead to consistent but inefficient estimates of the RE regression. The second one refers to serial correlation in the error term. The error term of the current period $v_{i t}$ could be correlated with the error term of the period before $v_{i t-1}$. We test for heteroscedasticity by running a regression using as dependent variable the squared error term and as independent variables all the variables in the model plus the prediction from the RE model squared and in higher exponential orders. Since the estimated coefficients for the added variables are significant, they explain some of the variance in the error term and we have to consider that the error terms is heteroscedastic. We further apply the Baltagi and Li (1995) test for autocorrelation of first order and find that autocorrelation is also present in the error term. We can cope with the problems, heteroscedasticity and autocorrelation, at the same time by applying a Feasible Generalized Least Squares (FGLS) estimator. The FGLS approach allows us to adjust the model to an autocorrelation structure of order 1 (AR1). The results of the FGLS estimation are shown in columns 5 to 6 (Table 1). In column 5 only autocorrelation was modeled and column 6 corrects for both autocorrelation and heteroscedasticity. Given the characteristics of our data this specification seems to be the one of the highest quality and we will refer to the model in column 6 to analyze the driving forces of $\mathrm{CO}_{2}$ emissions.

The estimated coefficients show the expected signs and the results confirm the findings from Martínez-Zarzoso (2008) except that our sample takes the high income countries as well into account. An increase in population by $1 \%$ leads to an increase in $\mathrm{CO}_{2}$ emissions by $1.32 \%$ and therefore the relationship is around unity as pointed out by Martínez-Zarzoso (2008). Our technology variable industrial activity shows the expected positive sign. This relationship shows that the higher the manufacturing output in GDP is, the higher are the emissions. In other words industrializing countries emit on average more $\mathrm{CO}_{2}$.

GDP shows a strong impact on emissions, an increase by $1 \%$ leads to an increase in emissions by $0.8 \%$. This relationship just confirms that the more output is produced, the more $\mathrm{CO}_{2}$ will be emitted. For the squared variable of GDP we find a negative but insignificant coefficient. In Figure 5 we illustrate the emission-income relationship graphically. We find steadily rising 
emissions with increasing GDP. Even though the growth rate in emissions is decreasing, there is still no turning point, where emissions would decline with rising GDP.

Figure 5 Scatter Plot $\mathrm{CO}_{2}$ Emissions and Income

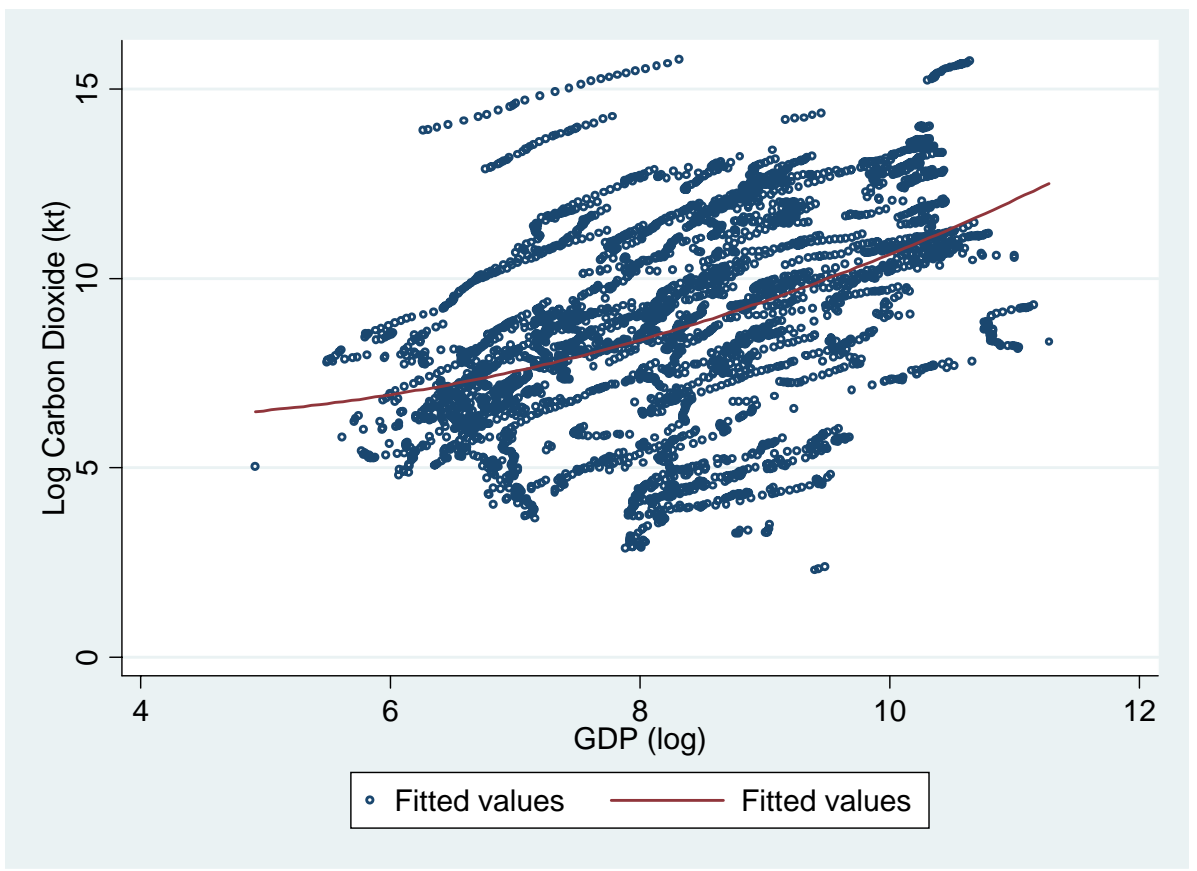

Source: Author's estimation

Besides technological change there are other ways to reduce emissions such as policies to regulate emissions. On the one hand, the results on the KyotoOb variable show a negative and significant effect, although the group of countries with emission reduction obligations is small and most of them have just ratified the Protocol in 2002. ${ }^{11}$ On the other hand, the CDM dummy variable is insignificant as well as the control variable for emission reductions from economies in transition. There are several possible reasons why we do not see an effect of those two later variables. One reason could be that it is still too early to look for an effect from CDM. Another issue is that we consider equality of slopes for all the explanatory variables in the above models. That is, we assume that countries are homogenous in their initial conditions. Since the countries in our sample are very heterogeneous, an increase in $1 \%$ of their GDP or population might show different effects for different countries. Therefore we group the countries by different income levels to take account for their different starting

\footnotetext{
${ }^{11}$ There is evidence, that most of the countries will not be able to fulfill their obligations in the first commitment round from 2008 until 2012 (see Appendix .4)
} 
positions on the EKC. If we still consider an EKC to exist, an increase in GDP might lead to a decrease in $\mathrm{CO}_{2}$ emissions in a high income country, meanwhile it might lead to an increase in emissions in a low income country. We therefore grouped the countries into four GDP groups: high, upper-middle, lower-middle and low. We estimate the same model as in column 6 of Table 1 for each sub-group.

Table 2 Results from the Static Model grouped by Income

\begin{tabular}{lrrrrr}
\hline & \multicolumn{5}{c}{ FGLS } \\
& \multicolumn{1}{c}{ All } & \multicolumn{1}{c}{ High } & Upper-Mid & Lower-Mid & \multicolumn{1}{c}{ Low } \\
\hline InPop & $1.321^{* * *}$ & $1.126^{* * *}$ & $1.588^{* * *}$ & $2.046^{* * *}$ & $0.224^{*}$ \\
& $(22.35)$ & $(10.98)$ & $(12.03)$ & $(15.58)$ & $(1.86)$ \\
InGDP & $0.798^{* * *}$ & $6.801^{* * *}$ & 2.121 & 0.702 & $-2.062^{* * *}$ \\
& $(5.67)$ & $(10.83)$ & $(1.53)$ & $(0.95)$ & $(4.54)$ \\
InGDP2 & -0.005 & $-0.320^{* * *}$ & -0.071 & 0.005 & $0.205^{* * *}$ \\
& $(0.53)$ & $(9.90)$ & $(0.91)$ & $(0.11)$ & $(6.17)$ \\
InIA & $0.088^{* * *}$ & $-0.084^{* *}$ & $0.159^{* * *}$ & $0.083^{* * *}$ & $0.126^{* * *}$ \\
& $(7.23)$ & $(2.30)$ & $(4.60)$ & $(2.95)$ & $(6.78)$ \\
KyotoOb & $-0.022^{* * *}$ & 0.011 & $-0.117^{* * *}$ & $-0.087 * *$ & \\
& $(2.98)$ & $(0.74)$ & $(3.68)$ & $(1.99)$ & \\
CDM & 0.010 & -0.009 & -0.000 & 0.023 & -0.059 \\
& $(0.79)$ & $(0.23)$ & $(0.01)$ & $(0.68)$ & $(1.46)$ \\
EIT & -0.032 & -0.099 & 0.009 & $3.606 * * *$ & \\
& $(1.03)$ & $(1.41)$ & $(0.18)$ & $(6.30)$ & \\
Time Dummies & yes & yes & yes & yes & yes \\
Country Dummies & yes & yes & yes & yes & yes \\
Constant & $-17.772^{* * *}$ & $-42.285^{* * *}$ & $-29.484^{* * *}$ & $-33.516^{* * *}$ & $12.491^{* * *}$ \\
& $(15.67)$ & $(13.10)$ & $(4.33)$ & $(7.81)$ & $(5.12)$ \\
Observations & 3265 & 663 & 688 & 863 & 1051 \\
Countries & 170 & 39 & 36 & 43 & 52 \\
\hline
\end{tabular}

Note: $\mathrm{t}$-statistics are in brackets $* * *, * * *$ denote significance at $10 \%, 5 \%$ and $1 \%$ level, respectively.

By dividing the countries into those groups we can show the differences between the driving forces of $\mathrm{CO}_{2}$ emissions among countries of different wealth concerning GDP. The results on population are different to the findings of Shi (2003) and Martínez-Zarzoso (2008) that found estimates lower than one for high-income countries and higher than one for the other groups. We find a coefficient slightly higher than one for high-income countries, in the interval 1.5-2 for middle income countries and a very low coefficient for low-income countries $(0.22)$.

GDP and GDP squared are only significant for low-income countries, where the relationship between $\mathrm{CO}_{2}$ emissions shows a U-shaped curve and for high-income countries, for which 
there is evidence of an EKC since the squared term of GDP is negative. We further outline the emission-income relationship in Figure 6.

\section{Figure 6 Scatter Plot $\mathrm{CO}_{2}$ and Income grouped by Income (Static Model)}
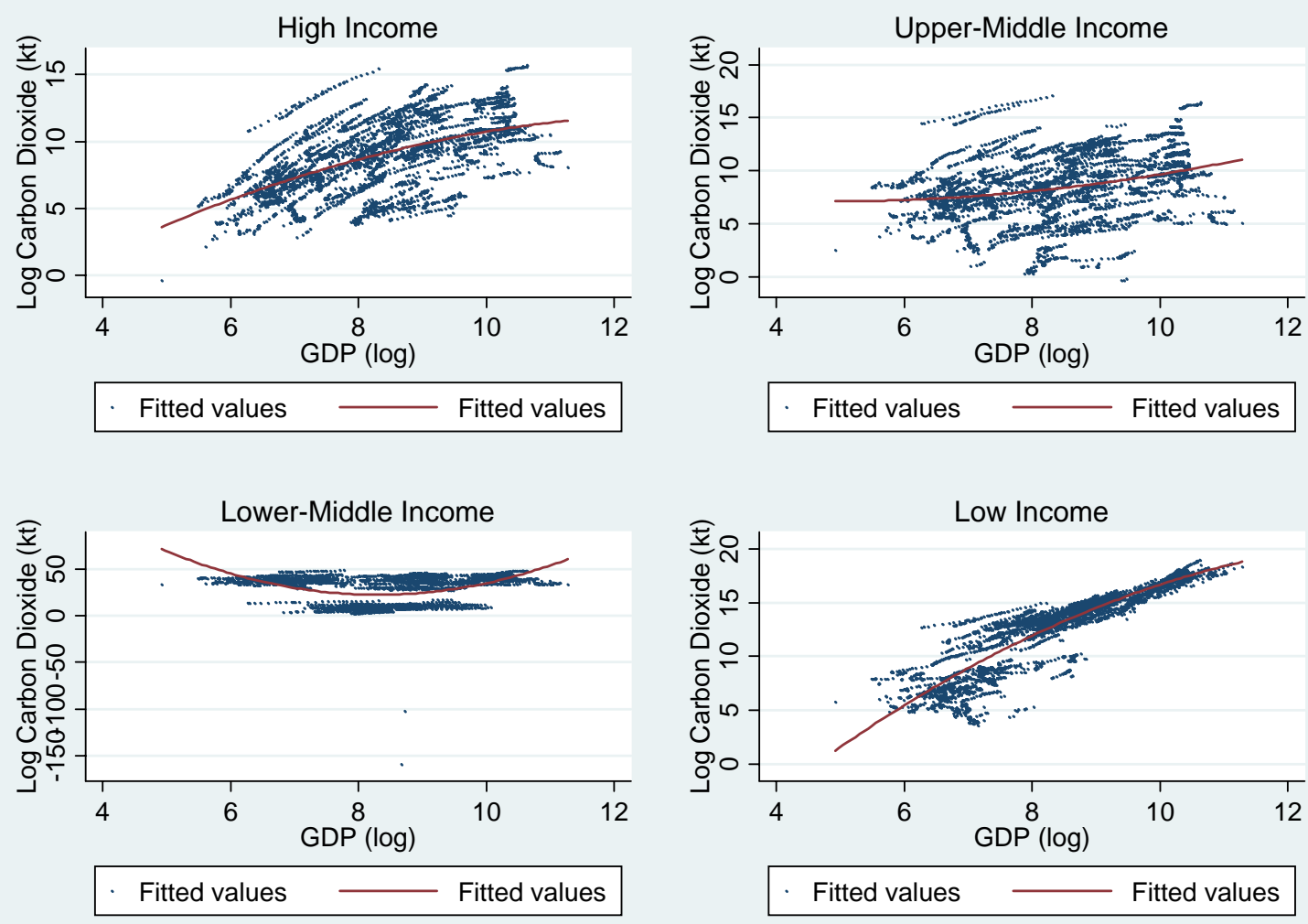

Source: Author's estimations

Industrial activity is significant among all country groups but only in the high-income countries it shows a negative sign. We could interpret this result using the technological change argument. High-income countries seem to apply end of pipe technology in their production chain and therefore they show on average lower $\mathrm{CO}_{2}$ emissions even with a high share of manufactures in their output.

In Table 2 we do observe an effect of the control variable for economies in transition, it is positive and significant for lower-middle income countries. This means that among the lowermiddle-income countries a country emits on average more $\mathrm{CO}_{2}$ if it is an economy in transition. Actually we would expect a negative coefficient due to economic recession in those countries after 1990. Zugravu et al. (2008) investigate to which extent emission reductions in economies in transition are due to their economic recession. They proof that 
besides reductions from economic slowdown, there is also a rise in $\mathrm{CO}_{2}$ emissions due to the economic catch up of those countries.

Finally, when grouping the countries by income and therefore making them more homogenous we find an effect from Kyoto Protocol on $\mathrm{CO}_{2}$ emissions for the middle-income countries, whereas we do not find an effect for high-income countries. This might be due to the fact that among the high-income countries most of them face emissions reduction obligations, meanwhile among the middle-income countries just a few face emission reduction obligations, which causes more variance in the data. Nevertheless, there is a significant and negative effect form Kyoto Protocol on $\mathrm{CO}_{2}$ emissions when looking at the whole sample.

With respect to the CDM variable, we find that the estimated coefficient is negative and significant at the 10 percent level for low-income countries, showing evidence of a reducing effect on emissions. As already stated above, it is still too early to find a strong and significant effect, since most of the projects started at the end of our sample.

\subsubsection{Dynamic Approach}

After analyzing $\mathrm{CO}_{2}$ emissions using a static model we turn into a dynamic specification of the model. There is growing evidence in the literature showing that the pollution-income relationship is a dynamic one. Agras and Chapman (1999), Aldy (2006), Egli and Steger (2007), Martínez-Zarzoso et al. (2007), Martínez-Zarzoso and Bengochea-Morancho (2004, 2003) are some examples. The dynamic approach assumes that today's $\mathrm{CO}_{2}$ emissions are driven by past ones. If a country emitted large amounts of $\mathrm{CO}_{2}$ last year, it is likely that this year's emissions will be high as well. The $\mathrm{CO}_{2}$ emissions of the last year therefore have an impact on this year's emissions. To measure this impact we introduce last year's $\mathrm{CO}_{2}$ emissions $\ln \mathrm{CO}_{t-1}$ as an additional explanatory variable in the model.

Dynamic models suffer from a bias, which is caused by the endogeneity of the lagged dependent variable. Since $\ln \mathrm{CO}_{2}$ is a function of $v_{i t}$, then $\ln \mathrm{CO}_{t-1}$ will be a function of $v_{i t}$ as well and therefore endogenous. To overcome this problem we use a Two Stage Least Squares Instrumental Variable (2SLS IV) estimator, similar to the Anderson Hsiao (AH) estimator. The AH estimator solves the endogeneity problem by using instruments for the lagendogenous variable $\left(\operatorname{lnCO} 2_{t-1}\right)$. The second lag of this variable can be used as a valid instrument in order to obtain consistent estimates. There is critique on the efficiency of the 
$\mathrm{AH}$ estimator since other instrumental variable estimators such as the Arellano Bond and Blundell Bond estimator use more instruments and are more efficient. We will use the $\mathrm{AH}$ estimator since the Arellano Bond and Blundell Bond estimator are possibly biased when the time dimension $t$ is large. We cover 35 years of $\mathrm{CO}_{2}$ observations and consider this to be a large $t$. Judson and Own (1996) compare the performance of the AH, the Arellano Bond, the Blundell Bond and the Least Square Dummy Variable (LSDV) estimator when $t$ is large. They come to the result that for a panel with large time dimension the AH estimator performs well. Bruno (2005) again compares the above mentioned estimators in the context of a large time dimension and develops a bias corrected LSDV estimator. We estimated our model with the corrected LSDV specification and compared it with the results from the AH estimator. Since the results turned out to be similar we decided to choose the AH estimator as our preferred model to be able to make a consistent comparison between our static model and the dynamic model. Just like in the static model we also formed income-groups.

Table 3 Results from the Dynamic Model grouped by Income

\begin{tabular}{|c|c|c|c|c|c|}
\hline & \multicolumn{5}{|c|}{2 SLS IV } \\
\hline & All & High & Upper-Mid & Lower-Mid & Low \\
\hline \multirow[t]{2}{*}{$\operatorname{lnCO} \mathrm{O}_{2-1}$} & $0.752 * * *$ & $0.558^{* * *}$ & $0.781 * * *$ & $0.750 * * *$ & $0.737 * * *$ \\
\hline & $(53.61)$ & (10.11) & (26.40) & (29.64) & (26.59) \\
\hline \multirow[t]{2}{*}{$\operatorname{lnPop}$} & $0.221 * * *$ & $0.537 * * *$ & 0.068 & $0.242 *$ & -0.019 \\
\hline & $(4.26)$ & (5.11) & $(0.71)$ & $(1.75)$ & $(0.15)$ \\
\hline \multirow[t]{2}{*}{ InGDP } & 0.111 & $2.907 * * *$ & -0.323 & 0.012 & 0.157 \\
\hline & $(1.03)$ & $(4.65)$ & $(0.38)$ & $(0.02)$ & $(0.44)$ \\
\hline \multirow[t]{2}{*}{$\operatorname{lnGDP}^{2}$} & 0.008 & $-0.137 * * *$ & 0.040 & 0.012 & 0.002 \\
\hline & $(1.11)$ & $(4.35)$ & $(0.81)$ & $(0.29)$ & $(0.09)$ \\
\hline \multirow[t]{2}{*}{$\ln I A$} & $0.074 * * *$ & $-0.061^{*}$ & $0.102 * * *$ & 0.009 & $0.093 * * *$ \\
\hline & (5.39) & (1.93) & $(3.40)$ & $(0.24)$ & (4.63) \\
\hline \multirow[t]{2}{*}{ KyotoOb } & -0.022 & 0.023 & $-0.076^{*}$ & -0.039 & \\
\hline & $(0.95)$ & $(0.75)$ & $(1.71)$ & $(0.18)$ & \\
\hline \multirow[t]{2}{*}{ CDM } & -0.004 & -0.029 & 0.029 & -0.004 & 0.026 \\
\hline & $(0.10)$ & $(0.22)$ & $(0.53)$ & $(0.05)$ & $(0.27)$ \\
\hline \multirow[t]{2}{*}{ EIT } & 0.063 & 0.076 & 0.065 & -2.197 & 0.000 \\
\hline & $(0.88)$ & $(0.76)$ & $(0.80)$ & $(0.69)$ & (.) \\
\hline Time Dummies & yes & yes & yes & yes & yes \\
\hline Country Dummies & yes & yes & yes & yes & yes \\
\hline \multirow[t]{2}{*}{ Constant } & $-2.592 * * *$ & $-19.227^{* * *}$ & 1.071 & & \\
\hline & (2.65) & $(5.37)$ & $(0.25)$ & & \\
\hline Observations & 3237 & 661 & 681 & 852 & 1043 \\
\hline Countries & 170 & 39 & 36 & 43 & 52 \\
\hline
\end{tabular}

Note: $\mathrm{t}$-statistics are in brackets $* * *$ and $* * *$ denote significance at $10 \%, 5 \%$ and $1 \%$ level, respectively. 
The lagged endogenous variable shows a strong and positive impact on $\mathrm{CO}_{2}$ emissions. Hence, last year's emissions have a strong impact on today's ones, which we did expect. Population becomes a weaker force in the model once dynamics are taken into account. An increase of population by $1 \%$ leads to a rise of $\mathrm{CO}_{2}$ emissions by 0.2 percent in the shortrun. $^{12}$ Grouping the countries by income as done in Table 2 (columns 2 to 5) shows that population has again its strongest positive impact on the high income countries contrary to the static model.

In Table 3, as in the static model, GDP is the driving force of emissions among high income countries. Figure 7 describes the emission-income relationship in the dynamic model, which shows a more steady increasing relationship for emissions with increasing GDP. An EKC is for $\mathrm{CO}_{2}$ is not found for high income countries, just as in the static model.

\section{Figure $7 \quad$ Scatter Plot $\mathrm{CO}_{2}$ and Income grouped by Income (Dynamic Model)}
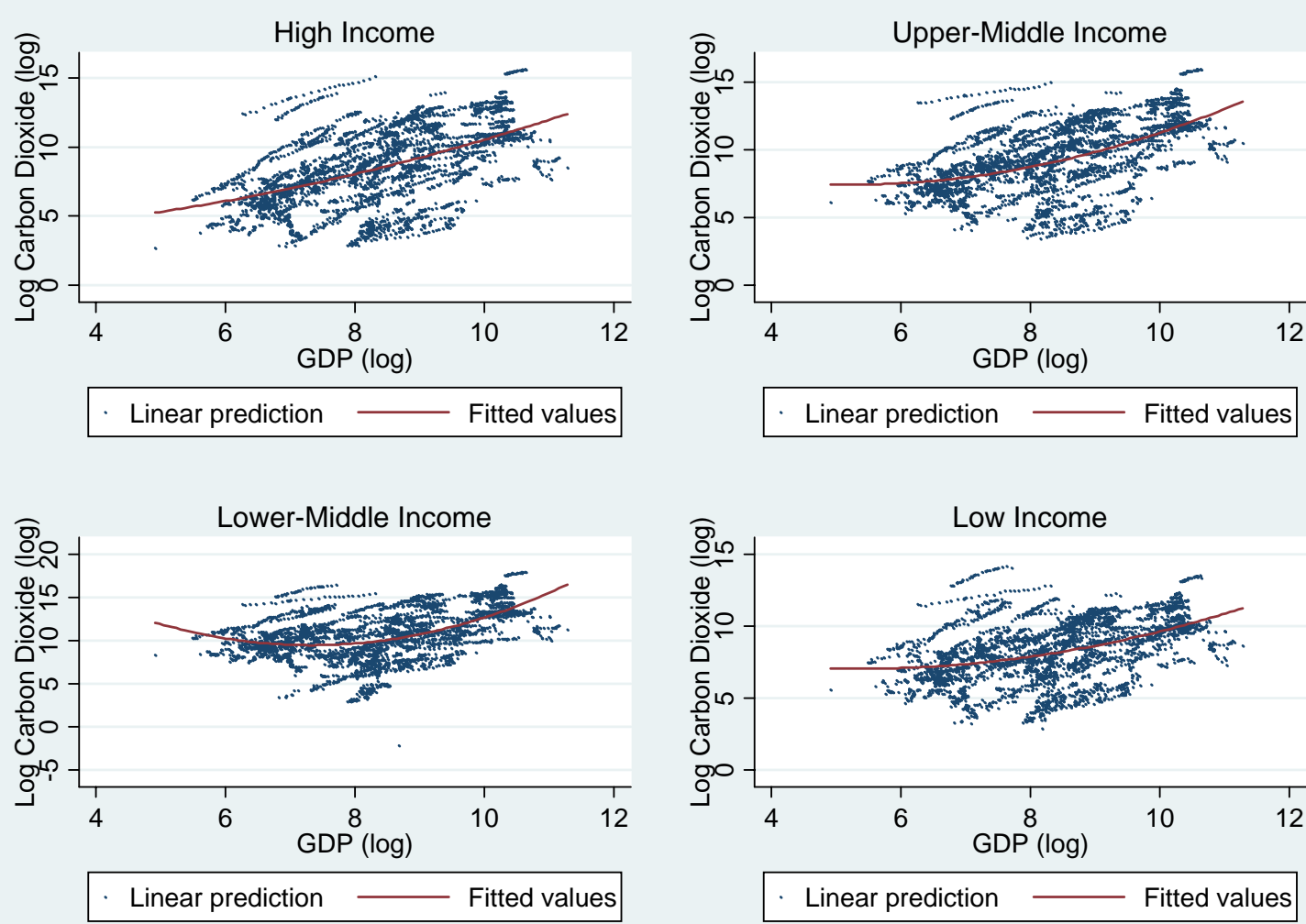

Source: Author's estimations

\footnotetext{
${ }^{12}$ For comparison one should estimate the long run coefficients.
} 
Industrial activity contributes only in high income countries to declining emissions, whereas it contributes to higher emissions in upper-middle- and low-income countries. Concerning the Kyoto variables there is weak evidence for upper-middle-income countries that they contribute to declining emissions according to the result of the dynamic model, but not for high- and lower-middle-income countries.

\section{Conclusion}

We analyzed two major questions. First we examined the relationship between $\mathrm{CO}_{2}$ emissions and income per capita of 123 countries over a period of 35 years. As a next task we examined the driving forces behind the emission-income relationship and tested for an effect of the Kyoto Protocol as a possible cause for lowering emissions among the countries with emission reduction obligations from the protocol or among the countries hosting CDM projects.

Our findings are twofold. First, we could not confirm an EKC for $\mathrm{CO}_{2}$ among all countries but for high-income countries there is evidence for future declining emissions. Still, rising GDP represents the main driving force behind rising emissions. This result cannot lead to the conclusion that one should attempt to slow down economic growth in developing countries, rather one should think about how to make this growth cleaner. The transfer of end of pipe technology reflects the idea of "tunneling" the emission-income relationship. Hence, it could contribute to omit high emission levels, which could cause irreversible damage. In line with the results of the static and the dynamic model we can conclude that better technology has a high potential to outweigh increases in $\mathrm{CO}_{2}$ emissions driven by GDP. Interesting in this context are the variables reflecting technological progress, such as industrial activity. By grouping countries over income it becomes evident that there is the possibility to reduce emissions by transferring end of pipe technology to poorer countries.

Second, concerning the impact of Kyoto Protocol in terms of potential emission reduction efforts or the implementation of CDM projects there might be evidence for an impact on emissions. We find an effect from Kyoto Protocol on $\mathrm{CO}_{2}$ emissions. Nevertheless, this negative effect of the protocol on $\mathrm{CO}_{2}$ emissions is small. Hence, there is still a long road to go and emission reduction goals might be still too loose. With respect to the Kyoto Protocol and its flexible mechanisms, the CDM represents a legal tool to buy CER from countries without emission reduction obligations. However, it also represents a tool for potential poverty reduction and sustainable development among middle and low income countries. 
Most of the current projects from the CDM projects are located in the energy sector since there are high rents of CER expected. This goes in line with our findings on industrial activity and represents the key component for future CDM projects, which could not only provide sustainable development, but also could have a high potential to contribute to poverty alleviation.

Finding an $\mathrm{EKC}$ for $\mathrm{CO}_{2}$ in a global approach is yet unlikely. The problem lies in the nature of the global, public good climate protection. There is little incentive to invest in the distribution of a global, public good, whose benefits will occur in terms of omitted damage from climate change in an uncertain future. Hence, there is a lack of incentives to participate in international climate policy. Kyoto II will have to present a solution to integrate more countries in a treaty or to establish an international taxing system on GHG emissions.

We find an emission reducing effect from Kyoto Protocol but could not find an emission reducing effect of our CDM variable. The reason might be that it is yet too early or that the $\mathrm{CDM}$ has no significant contribution to the reduction of $\mathrm{CO}_{2}$ emissions. But results from the four country groups on industrial activity could indicate how to design future CDM projects to be sustainable. Those results indicate that there is a higher potential to reduce emissions in middle or low income countries than in high income countries. In other words emissions can be reduced at much lower cost in middle or low income countries. Therefore focusing CDM projects which transfer technology to make the energy use more efficient could contribute to sustainable development.

After all the first commitment round of Kyoto Protocol has just started this year and we could only see little impact on global emissions from the protocol. This opens the possibility to redo the investigation at hand in 2012 when the first commitment round has closed. The task for Kyoto II will be to provide incentives for all countries to participate in international climate change agreements and therefore taking into account their diversities. 


\section{References}

Agras, J. and Chapman, D. (1999), "A Dynamic Approach to the Environmental Kuznets Curve Hypothesis", Ecological Economics 28, 267-277.

Aldy, J.E. (2006), "Per Capita Carbon Dioxide Emissions - Convergence or Divergence?", Environmental and Resource Economics 33, 533-555.

Baiocchi, G. and di Falco, S. (2001), Investigating the shape of the EKC - A Nonparametric Approach, Fondazione Eni Enrico Mattei, Working Paper 66.

Baltagi, B.H. and Li, Q. (1995), "Testing AR1 against MA1 Disturbances in an Error Component Model", Journal of Econometrics 68, 133-151.

Bretschger, L. and Smulders, S. (2007), Sustainable Resource Use and Economic Dynamics, Springer.

Bruno, G.S.F. (2005), Estimation and Inference in Dynamic Unbalanced Panel Data Models with Small Number of Individuals, Centro di Ricerca sui Processi di Innovazione e Internazionalizzazione, Working Paper 165.

Cole, M.A. and Neumeyer, E. (2004), "Examining the Impact of Demographic Factors on Air Pollution", Population and Environment 26, 5-21.

Cole, M.A.; Rayner A.J. and Bates, J.M. (1997), „The Environmental Kuznets Curve - An Empirical Analysis“, Environment and Development Economics 2, 401-416.

Cramer, J.C. (1998), "Population Growth and Air Quality in California", Demography 35, 4556.

Cramer, J.C. and Cheney R.P. (2000), "Lost in the Ozone - Population Growth and Ozone in California", Population and Environment 21, 315-338.

Dietz, T. and Rosa, E.A. (1997), "Effects of Population and Affluence on $\mathrm{CO}_{2}$ Emissions", Proceedings of the National Academy of Sciences 94, 175-179.

Dijkgraaf, E. and Vollebergh, H.R.J. (2001), A Note on Testing for Environmental Kuznets Curves, Fondazione Eni Enrico Mattei, Working Paper 63.

Dutt, K. (2009), "Governance, Institutions and the Environment-Income Relationship - A Cross-Country Study", Environment, Development and Sustainability, forthcoming.

Ehrlich, P. and Holdren, J. (1970), "The People Problem", Saturday Review 4, 42-43.

Egli, H. and Steger, T.M. (2007), "A Dynamic Model of the Environmental Kuznets Curve Turning Point and Public Policy", in Bretschger, L. and Smulders, S. (eds.), Sustainable Resource Use and Economic Dynamics, 17-34.

Ellis, J. et al. (2007), "CDM - Taking Stock and Looking Forward", Energy Policy 35, 15-28.

Fuhr, H.; Lederer, M. and Schröder, M. (2008), "Neue Formen des Regierens und Klimaschutzes durch Private Unternehmen?", GIGA Focus Global 7.

Galeotti, M.; Lanza, A. (1999), Richer and Cleaner? - A Study on Carbon Dioxide Emissions in Developing Countries, Fondazione Eni Enrico Mattei, Working Paper 87.

Grossman, G.M. and Krueger, A.B. (1995), "Economic Growth and the Environment", The Quarterly Journal of Economics 110, 353-377.

Heerink, N.; Mulatu, A. and Bulte, E. (2001), "Income Inequality and the Environment Aggregation Bias in Environmental Kuznets Curves", Ecological Economics 38, 359367.

Holtz-Eakin, D. and Selden, T.M. (1995), "Stoking the Fires? $\mathrm{CO}_{2}$ Emissions and Economic Growth", Journal of Public Economics 57, 85-101.

Judson, R.A. and Owen, A.L. (1996), "Estimating Dynamic Panel Data Models - A Practical Guide for Macroeconomists", Federal Reserve Board of Governors.

Kuznets, S. (1955), "Economic Growth and Income Inequality", The American Economic Review 45, 1-28.

Lecocq, F. and Ambrosi P. (2007), "The Clean Development Mechanism - History, Status and Prospects", Review of Environmental Economics and Policy 1, 134-151. 
Lieb, C.M. (2003), The Environmental Kuznets Curve - A Survey of the Empirical Evidence and of Possible Causes, University of Heidelberg, Discussion Paper Series 391.

Liu, X. (2008), "Rent Extraction with a Type-by-Type Scheme - An Instrument to Incorporate Sustainable Development into the CDM", Energy Policy 36, 1873-1878.

Martínez-Zarzoso, I. (2008), The Impact of Urbanization on CO2 Emissions, Fondazione Eni Enrico Mattei, Working Paper 50.

Martínez-Zarzoso, I. and Bengochea-Morancho, A. (2004), "Pooled Mean Group Estimation of an Environmental Kuznets Curve for $\mathrm{CO}_{2}$ ", Economics Letters 82, 121-126.

Martínez-Zarzoso, I.; Bengochea-Morancho, A. and Morales-Lage, R. (2007), "The Impact of Population and CO2 Emissions - Evidence from European Countries”, Environmental and Resource Economics 38, 497-512.

Moomay W.R. and Unruh, G.C. (1997), "Are Environmental Kuznets Curves Misleading Us? The Case of $\mathrm{CO}_{2}$ Emissions", Environment and Development Economics 2, 451-463.

Panayotou, T. (1997), "Demystifying the Environmental Kuznets Curve - Turning a Black Box into a Policy Tool", Environment and Development Economics 2, 465-484.

Panayotou, T.; Peterson, A. and Sachs J. (2000), Is the Environmental Kuznets Curve Driven by Structural Change? What Extended Time Series May Imply for Developing Countries, CAER II, Discussion Paper 80.

Rose, A.K. and Spiegel, M.M. (2008), "Non-Economic Engagement and International Exchange - The Case of Environmental Treaties", NBER working paper 13988.

Roberts, J.T. and Grimes, P.E. (1997), "Carbon Intensity and Economic Development 196291 - A Brief Exploration of the Environmental Kuznets Curve", World Development 25, 191-198.

Roca J.; Padilla, E; Farré, M. and Galletto, V. (2001), "Economic Growth and Atmospheric Pollution in Spain - Discussing the Environmental Kuznets Curve Hypothesis", Ecological Economics 39, 85-99.

Schmalensee, R.; Stoker, T.M. and Judson, R.A. (1998), "World Carbon Dioxide Emissions: 1950-2050", Revenue of Economics and Statistics 80, 15-27

Schneider, M.; Holzer, A. and Hoffmann, V.H. (2008), "Understanding the CDM's Contribution to Technology Transfer", Energy Policy 36, 2930-2938.

Schubert, R.; Blasch, J. and Hoffmann, K. (2007), "Environmental Protection, Energy Policy and Poverty Reduction - Synergies of an Integrated Approach", Institute for Environmental Decisions, Working Paper 1.

Selden, T.M. and Song, D. (1994), "Environmental Quality and Development - Is There a Kuznets Curve for Air Pollution Emissions?", Journal of Environmental Economics and Management 27, 147-162.

Sengupta, R. (1996), "CO2 Emission-Income Relationship - Policy Approach for Climate Control", Pacific and Asian Journal of Energy 7, 207-229

Shafik, N. and Bandyopadhyay, S. (1992), Economic Growth and Environmental Quality Time Series and Cross-Country Evidence, The World Bank, Working Paper No 904.

Shi, A. (2003), "The Impact of Population Pressure on Global Carbon Dioxide Emissions, 1975-1996 - Evidence from Pooled Cross Country-Data", Ecological Economics 44, $29-42$.

Swinton, J.A. and Sarkar, A. (2008), "The Benefits of the Kyoto Protocol to Developing Countries", Environment, Development and Sustainability, forthcoming.

Tucker, M. (1995), "Carbon Dioxide Emissions and Global GDP”, Ecological Economics 15, 215-223.

UNEP Risoe Centre (2008), http://www.cdmpipeline.org/, 01.07.08.

UNFCCC (2008), http://unfccc.int/2860.php, 01.07.08. 
UNFCCC (1997), Kyoto Protocol to the United Nations Framework Convention on Climate Change, UN Framework Convention on Climate Change, http://unfccc.int/resource/docs/convkp/kpeng.pdf.

UNFCCC (1992), United Nations Framework Convention on Climate Change, UN Framework Convention on Climate Change, http://unfccc.int/resource/docs/convkp/conveng.pdf.

UNWCED (1987), Our Common Future, United Nations (New York).

York, R.; Rosa, E.A. and Dietz, T. (2003), "STIRPAT, IPAT and ImPACT - Analytic Tools for Unpacking the Driving Forces of Environmental Impacts", Ecological Economics 46, 351-365.

World Bank (2008), World Development Indicators 2008, Data CD.

Zugravu, N.; Millock, K. and Duchene, G. (2008), "The Factors behind $\mathrm{CO}_{2}$ Emission Reduction in Transition Economies", Fondazione Eni Enrico Mattei, Working Paper58. 


\section{Appendix}

\section{Appendix 1 Literature on the Relationship between $\mathrm{CO}_{2}$ and Income}

\begin{tabular}{|c|c|c|c|}
\hline Authors & Turning Points & EKC & Countries \\
\hline \multirow[t]{2}{*}{ Shafik and Bandyopadhyay (1992) } & \$7 Million & No & $118-153$ \\
\hline & $\$ 35428$ (level) - \$8 Million & & \\
\hline Holtz-Eakin and Selden (1995) & $(\log s)$ & Yes & 108 \\
\hline Tucker (1995) & Decreasing over Time & In 11 Years & 137 \\
\hline Sengupta (1996) & $\$ 8740$ & Yes & 16 Developed and Developing \\
\hline Cole Rayner and Bates (1997) & $\$ 25100$ (levels) - \$62700 (logs) & Yes & 7 World Regions \\
\hline Moomay and Unruh (1997) & $\$ 12813$ & N-Shaped & 16 Developed \\
\hline Roberts and Grimes 1997) & $\$ 8000-\$ 10000$ & Yes, after the $70 \mathrm{~s}$ & Developed and Developing \\
\hline Schmalensee, Stoker and Judson (1998) & within sample & Yes & 141 \\
\hline Agras and Chapman (1999) & $\$ 13630$ & No & 34 \\
\hline Galeotti and Lanza (1999) & $\$ 15073-\$ 21757$ & Yes & 110 \\
\hline Panayotou, Peterson and Sachs (2000) & $\$ 29732-\$ 40906(1950-1990)$ & Yes for Developed & 17 Developed \\
\hline Heerink et al. (2001) & $\$ 68871$ & Yes & $118-153$ \\
\hline Roca et al. (2001) & GDP non sig & No & Spain \\
\hline Baiocchi and di Falco (2001) & GDP non sig & No & 160 \\
\hline Bengochea et al. (2001) & $\$ 24427-\$ 73170$ & For some Countries & UE \\
\hline Dijkgraaf and Vollebergh (2001) & $\$ 20647$ & Yes 5 Rich Countries & $24 \mathrm{OECD}$ \\
\hline \multicolumn{4}{|l|}{ Martínez-Zarzoso and Bengochea- } \\
\hline Morancho (2004) & $\$ 4914-\$ 18364$ & N-Shaped & 22 OECD \\
\hline
\end{tabular}

Source: Martínez-Zarzoso et al. (2007), p.508, f. 


\section{Appendix 2 List of the Countries from the Panel grouped by Income}

\begin{tabular}{|c|c|c|c|}
\hline High Income & Upper-middle Income & Lower-Middle Income & Low Income \\
\hline Andorra & American Samoa & Albania & Afghanistan \\
\hline Antigua and Barbuda & Argentina & Algeria & Bangladesh \\
\hline Aruba & Belize & Angola & Benin \\
\hline Bahamas, The & Botswana & Armenia & Burkina Faso \\
\hline Bahrain & Brazil & Azerbaijan & Burundi \\
\hline Barbados & Bulgaria & Belarus & Cambodia \\
\hline Bermuda & Chile & Bhutan & Central African Republic \\
\hline Brunei Darussalam & Costa Rica & Bolivia & Chad \\
\hline Cayman Islands & Croatia & Bosnia and Herzegovina & Comoros \\
\hline Channel Islands & Dominica & Cameroon & Congo, Dem. Rep. \\
\hline Cyprus & Equatorial Guinea & Cape Verde & Côte d'Ivoire \\
\hline Estonia & Gabon & China & Eritrea \\
\hline Faeroe Islands & Grenada & Colombia & Ethiopia \\
\hline French Polynesia & Hungary & Congo, Rep. & Gambia, The \\
\hline Greenland & Kazakhstan & Cuba & Ghana \\
\hline Guam & Latvia & Djibouti & Guinea \\
\hline Hong Kong, China & Lebanon & Dominican Republic & Guinea-Bissau \\
\hline Isle of Man & Libya & Ecuador & Haiti \\
\hline Israel & Lithuania & Egypt, Arab Rep. & India \\
\hline Kuwait & Malaysia & El Salvador & Kenya \\
\hline Liechtenstein & Mauritius & Fiji & Korea, Dem. Rep. \\
\hline Macao, China & Mayotte & Georgia & Kyrgyz Republic \\
\hline Malta & Mexico & Guatemala & Lao PDR \\
\hline Monaco & Montenegro & Guyana & Liberia \\
\hline Netherlands Antilles & Northern Mariana Islands & Honduras & Madagascar \\
\hline New Caledonia & Oman & Indonesia & Malawi \\
\hline Puerto Rico & Palau & Iran, Islamic Rep. & Mali \\
\hline Qatar & Panama & Iraq & Mauritania \\
\hline San Marino & Poland & Jamaica & Mongolia \\
\hline Saudi Arabia & Romania & Jordan & Mozambique \\
\hline Singapore & Russian Federation & Kiribati & Myanmar \\
\hline Slovenia & Serbia & Lesotho & Nepal \\
\hline Trinidad and Tobago & Seychelles & Macedonia, FYR & Niger \\
\hline United Arab Emirates & Slovak Republic & Maldives & Nigeria \\
\hline Virgin Islands (U.S.) & South Africa & Marshall Islands & Pakistan \\
\hline Australia & St. Kitts and Nevis & Micronesia, Fed. Sts. & Papua New Guinea \\
\hline
\end{tabular}

Source: WDI (2008) 
Appendix 2 List of the Countries from the Panel grouped by Income (Continued)

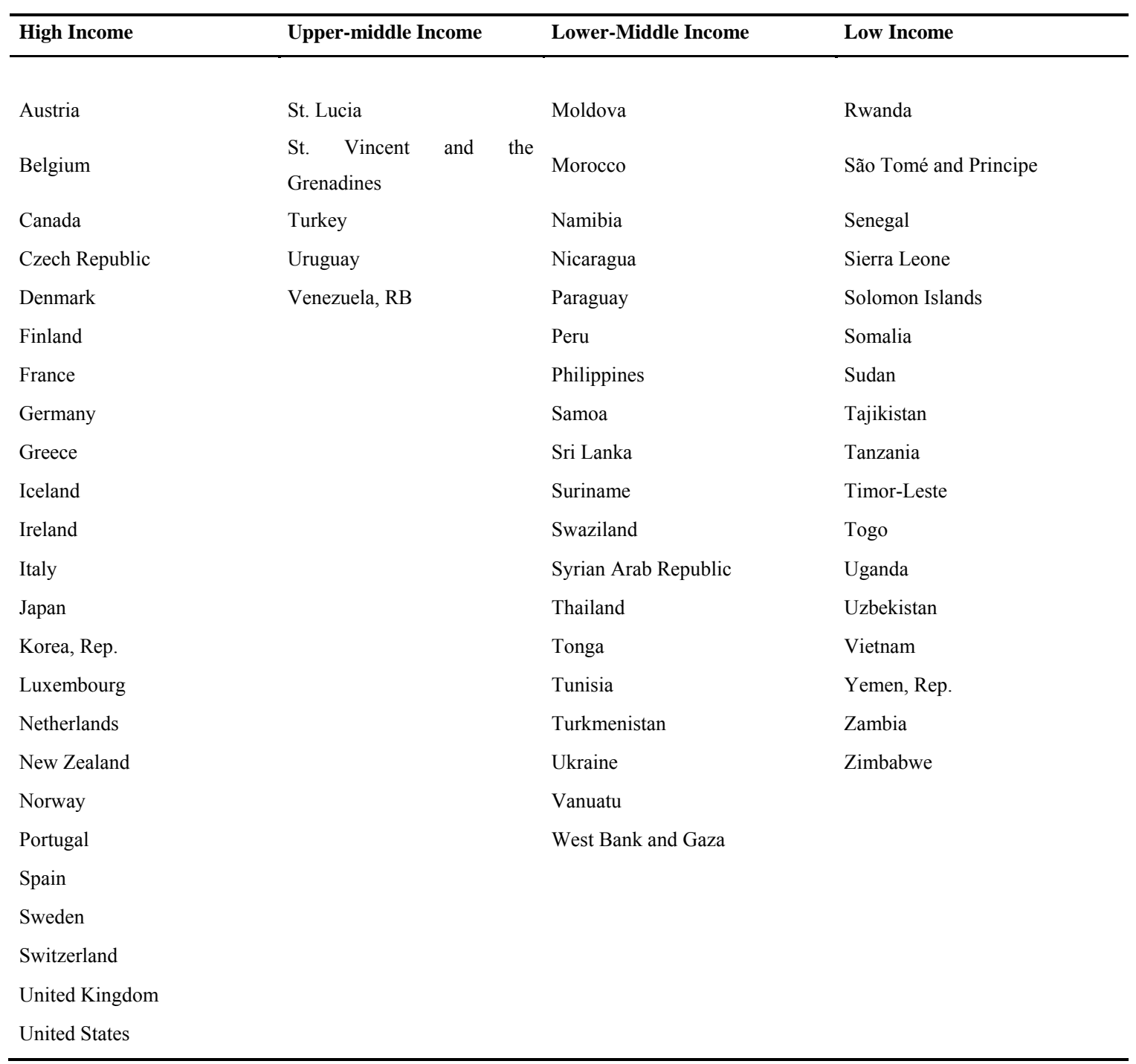

Source: WDI (2008)

Appendix 3 Economies in Transition by the UNFCCC (1992)

\begin{tabular}{ll}
\hline Bulgaria & Poland \\
Croatia & Romania \\
Czech Republic & Russian Federation \\
Estonia & Slovakia \\
Hungary & Slovenia \\
Latvia & \\
Lithuania & \\
\hline
\end{tabular}

Source: UNFCCC (1992, p.23) 


\section{Appendix 4 Cross Correlations of the Variables}

\begin{tabular}{rccccccc}
\hline & $\operatorname{lnCO}_{2}$ & $\operatorname{lnPop}$ & $\operatorname{lnGDP}$ & $\operatorname{lnIA}$ & KyotoOb & CDM & EIT \\
\hline $\operatorname{lnCO}_{2}$ & 1.0000 & & & & & & \\
$\operatorname{lnPop}$ & 0.7538 & 1.0000 & & & & & \\
$\operatorname{lnGDP}$ & 0.4703 & -0.1543 & 1.0000 & & & & \\
$\operatorname{lnIA}$ & 0.5520 & 0.4274 & 0.2738 & 1.0000 & & & \\
KyotoOb & 0.1566 & 0.0446 & 0.2332 & 0.0956 & 1.0000 & & \\
CDM & 0.0771 & 0.0778 & 0.0235 & 0.0457 & -0.0135 & 1.0000 & \\
EIT & 0.1671 & 0.0323 & 0.1495 & 0.2165 & 0.2381 & -0.0183 & 1.0000 \\
\hline
\end{tabular}

Source: WDI (2008)

\section{Appendix 5 Summary Statistics}

\begin{tabular}{rccrrr}
\hline Variable & \multicolumn{1}{l}{ Obs } & \multicolumn{1}{l}{ Mean } & \multicolumn{1}{l}{ Std. Dev. } & \multicolumn{1}{c}{ Min } & \multicolumn{1}{c}{ Max } \\
\hline CO $_{2}$ & 5479 & 104291.5 & 445707 & 0 & 6044023 \\
Pop & 6317 & $2.66 \mathrm{e}+07$ & $1.05 \mathrm{e}+08$ & 19700 & $1.31 \mathrm{e}+09$ \\
GDP & 4438 & 9124.454 & 10743.64 & 136.519 & 79031.6 \\
IA & 4206 & 14.72113 & 8.180407 & 0.289975 & 45.97157 \\
KyotoOb & 6897 & 0.028998 & 0.167813 & 0 & 1 \\
CDM & 6897 & 0.020444 & 0.141523 & 0 & 1 \\
EIT & 6897 & 0.032478 & 0.177279 & 0 & 1 \\
\hline
\end{tabular}

Source: WDI (2008)

\section{Appendix 6 Extended Summary Statistics}

\begin{tabular}{|c|c|c|c|c|c|c|}
\hline Variable & & Mean & Std. Dev. & Min & Max & Observations \\
\hline \multirow[t]{3}{*}{$\mathrm{CO}_{2}$} & overall & 104291.5 & 445707 & 0 & 6044023 & $\mathrm{~N}=5479$ \\
\hline & between & & 431278.3 & 26.0073 & 5010215 & $\mathrm{n}=195$ \\
\hline & within & & 90945 & -1242835 & 2622157 & $\mathrm{~T}=28.0974$ \\
\hline \multirow[t]{3}{*}{ Pop } & overall & $2.66 \mathrm{e}+07$ & $1.05 \mathrm{e}+08$ & 19700 & $1.31 \mathrm{e}+09$ & $\mathrm{~N}=6317$ \\
\hline & between & & $1.02 \mathrm{e}+08$ & 20000 & $1.13 \mathrm{e}+09$ & $\mathrm{n}=209$ \\
\hline & within & & $1.49 \mathrm{e}+07$ & $-2.19 \mathrm{e}+08$ & $2.78 \mathrm{e}+08$ & $\mathrm{~T}=30.2249$ \\
\hline \multirow[t]{3}{*}{ GDP } & overall & 9124.454 & 10743.64 & 136.519 & 79031.6 & $\mathrm{~N}=4438$ \\
\hline & between & & 10792.99 & 409.5149 & 64680.78 & $\mathrm{n}=180$ \\
\hline & within & & 2.772 .621 & -10841.34 & 35707.14 & $\mathrm{~T}=24.6556$ \\
\hline \multirow[t]{3}{*}{ IA } & overall & 14.72113 & 8.180407 & 0.2899752 & 45.97157 & $\mathrm{~N}=4206$ \\
\hline & between & & 7.697575 & 0.3968254 & 38.33099 & $\mathrm{n}=183$ \\
\hline & within & & 3.309322 & -.0848964 & 37.21212 & $\mathrm{~T}=22.9836$ \\
\hline \multirow[t]{3}{*}{ KyotoOb } & overall & 0.0289981 & 0.1678133 & 0 & 1 & $N=6897$ \\
\hline & between & & 0.0657965 & 0 & 0.2121212 & $\mathrm{n}=209$ \\
\hline & within & & 0.1544416 & -0.1831231 & 0.9683921 & $\mathrm{~T}=33$ \\
\hline \multirow[t]{3}{*}{ CDM } & overall & 0.0204437 & 0.1415225 & 0 & 1 & $\mathrm{~N}=6897$ \\
\hline & between & & 0.0396372 & 0 & 0.1515152 & $\mathrm{n}=209$ \\
\hline & within & & 0.1358853 & -.1310715 & 0.9901406 & $\mathrm{~T}=33$ \\
\hline \multirow[t]{3}{*}{ EIT } & overall & 0.0324779 & 0.1772784 & 0 & 1 & $N=6897$ \\
\hline & between & & 0.1215018 & 0 & 0.4848485 & $\mathrm{n}=209$ \\
\hline & within & & 0.1293579 & -0.4523706 & 0.5476294 & $\mathrm{~T}=$ \\
\hline
\end{tabular}

Source: WDI (2008) 


\section{CESifo Working Paper Series}

for full list see www.cesifo-group.org/wp

(address: Poschingerstr. 5, 81679 Munich, Germany, office@cesifo.de)

2693 Patricia Funk and Christina Gathmann, Does Direct Democracy Reduce the Size of Government? New Evidence from Historical Data, 1890-2000, June 2009

2694 Kirsten Wandschneider and Nikolaus Wolf, Shooting on a Moving Target: Explaining European Bank Rates during the Interwar Period, June 2009

2695 J. Atsu Amegashie, Third-Party Intervention in Conflicts and the Indirect Samaritan's Dilemma, June 2009

2696 Enrico Spolaore and Romain Wacziarg, War and Relatedness, June 2009

2697 Steven Brakman, Charles van Marrewijk and Arjen van Witteloostuijn, Market Liberalization in the European Natural Gas Market - the Importance of Capacity Constraints and Efficiency Differences, July 2009

2698 Huifang Tian, John Whalley and Yuezhou Cai, Trade Sanctions, Financial Transfers and BRIC's Participation in Global Climate Change Negotiations, July 2009

2699 Axel Dreher and Justina A. V. Fischer, Government Decentralization as a Disincentive for Transnational Terror? An Empirical Analysis, July 2009

2700 Balázs Égert, Tomasz Koźluk and Douglas Sutherland, Infrastructure and Growth: Empirical Evidence, July 2009

2701 Felix Bierbrauer, Optimal Income Taxation and Public Goods Provision in a Large Economy with Aggregate Uncertainty, July 2009

2702 Marc Gronwald, Investigating the U.S. Oil-Macroeconomy Nexus using Rolling Impulse Responses, July 2009

2703 Ali Bayar and Bram Smeets, Government Deficits in the European Union: An Analysis of Entry and Exit Dynamics, July 2009

2704 Stergios Skaperdas, The Costs of Organized Violence: A Review of the Evidence, July 2009

2705 António Afonso and Christophe Rault, Spend-and-tax: A Panel Data Investigation for the EU, July 2009

2706 Bruno S. Frey, Punishment - and beyond, July 2009

2707 Michael Melvin and Mark P. Taylor, The Crisis in the Foreign Exchange Market, July 2009 
2708 Firouz Gahvari, Friedman Rule in a Model with Endogenous Growth and Cash-inadvance Constraint, July 2009

2709 Jon H. Fiva and Gisle James Natvik, Do Re-election Probabilities Influence Public Investment?, July 2009

2710 Jarko Fidrmuc and Iikka Korhonen, The Impact of the Global Financial Crisis on Business Cycles in Asian Emerging Economies, July 2009

2711 J. Atsu Amegashie, Incomplete Property Rights and Overinvestment, July 2009

2712 Frank R. Lichtenberg, Response to Baker and Fugh-Berman's Critique of my Paper, "Why has Longevity Increased more in some States than in others?", July 2009

2713 Hans Jarle Kind, Tore Nilssen and Lars Sørgard, Business Models for Media Firms: Does Competition Matter for how they Raise Revenue?, July 2009

2714 Beatrix Brügger, Rafael Lalive and Josef Zweimüller, Does Culture Affect Unemployment? Evidence from the Röstigraben, July 2009

2715 Oliver Falck, Michael Fritsch and Stephan Heblich, Bohemians, Human Capital, and Regional Economic Growth, July 2009

2716 Wladimir Raymond, Pierre Mohnen, Franz Palm and Sybrand Schim van der Loeff, Innovative Sales, R\&D and Total Innovation Expenditures: Panel Evidence on their Dynamics, July 2009

2717 Ben J. Heijdra and Jochen O. Mierau, Annuity Market Imperfection, Retirement and Economic Growth, July 2009

2718 Kai Carstensen, Oliver Hülsewig and Timo Wollmershäuser, Price Dispersion in the Euro Area: The Case of a Symmetric Oil Price Shock, July 2009

2719 Katri Kosonen and Gaëtan Nicodème, The Role of Fiscal Instruments in Environmental Policy, July 2009

2720 Guglielmo Maria Caporale, Luca Onorante and Paolo Paesani, Inflation and Inflation Uncertainty in the Euro Area, July 2009

2721 Thushyanthan Baskaran and Lars P. Feld, Fiscal Decentralization and Economic Growth in OECD Countries: Is there a Relationship?, July 2009

2722 Nadia Fiorino and Roberto Ricciuti, Interest Groups and Government Spending in Italy, 1876-1913, July 2009

2723 Andreas Wagener, Tax Competition, Relative Performance and Policy Imitation, July 2009

2724 Hans Fehr and Fabian Kindermann, Pension Funding and Individual Accounts in Economies with Life-cyclers and Myopes, July 2009 
2725 Ernesto Reuben and Arno Riedl, Enforcement of Contribution Norms in Public Good Games with Heterogeneous Populations, July 2009

2726 Kurt Schmidheiny and Marius Brülhart, On the Equivalence of Location Choice Models: Conditional Logit, Nested Logit and Poisson, July 2009

2727 Bruno S. Frey, A Multiplicity of Approaches to Institutional Analysis. Applications to the Government and the Arts, July 2009

2728 Giovanni Villani, A Strategic R\&D Investment with Flexible Development Time in Real Option Game Analysis, July 2009

2729 Luca Di Corato and Michele Moretto, Investing in Biogas: Timing, Technological Choice and the Value of Flexibility from Inputs Mix, July 2009

2730 Gilad D. Aharonovitz, Nathan Skuza and Faysal Fahs, Can Integrity Replace Institutions? Theory and Evidence, July 2009

2731 Michele Moretto and Sergio Vergalli, Managing Migration through Conflicting Policies: an Option-theory Perspective, July 2009

2732 Volker Nitsch, Fly or Cry: Is Airport Noise Costly?, July 2009

2733 Francesco Cinnirella and Joachim Winter, Size Matters! Body Height and Labor Market Discrimination: A Cross-European Analysis, July 2009

2734 Samuel Bowles and Sandra Polanía Reyes, Economic Incentives and Social Preferences: A Preference-based Lucas Critique of Public Policy, July 2009

2735 Gary Burtless, Lessons of the Financial Crisis for the Design of National Pension Systems, July 2009

2736 Helmuth Cremer, Firouz Gahvari and Pierre Pestieau, Fertility, Human Capital Accumulation, and the Pension System, July 2009

2737 Hans Jarle Kind and Frank Stähler, Market Shares in Two-Sided Media Industries, July 2009

2738 Pamela Campa, Alessandra Casarico and Paola Profeta, Gender Culture and Gender Gap in Employment, August 2009

2739 Sebastian Gechert, Supplementary Private Health Insurance in Selected Countries: Lessons for EU Governments?, August 2009

2740 Leif Danziger, Endogenous Monopsony and the Perverse Effect of the Minimum Wage in Small Firms, August 2009

2741 Yan Dong and John Whalley, A Third Benefit of Joint Non-OPEC Carbon Taxes: Transferring OPEC Monopoly Rent, August 2009 
2742 Valentina Bosetti, Carlo Carraro and Massimo Tavoni, Climate Change Mitigation Strategies in Fast-Growing Countries: The Benefits of Early Action, August 2009

2743 Christina Felfe, The Willingness to Pay for Job Amenities: Evidence from Mothers' Return to Work, August 2009

2744 Jörg Franke, Christian Kanzow, Wolfgang Leininger and Alexandra Väth, Effort Maximization in Asymmetric N-Person Contest Games, August 2009

2745 Bruno S. Frey and Paolo Pamini, Making World Heritage Truly Global: The Culture Certificate Scheme, August 2009

2746 Frank N. Caliendo, Is Social Security behind the Collapse of Personal Saving?, August 2009

2747 Caterina Liesegang and Marco Runkel, Corporate Income Taxation of Multinationals and Fiscal Equalization, August 2009

2748 Chrysovalantou Milliou and Apostolis Pavlou, Upstream Horizontal Mergers and Efficiency Gains, August 2009

2749 Rüdiger Pethig and Christian Wittlich, Interaction of Carbon Reduction and Green Energy Promotion in a Small Fossil-Fuel Importing Economy, August 2009

2750 Kai Carstensen, Oliver Hülsewig and Timo Wollmershäuser, Monetary Policy Transmission and House Prices: European Cross-country Evidence, August 2009

2751 Olaf Posch, Explaining Output Volatility: The Case of Taxation, August 2009

2752 Beatrice Scheubel, Daniel Schunk and Joachim Winter, Don't Raise the Retirement Age! An Experiment on Opposition to Pension Reforms and East-West Differences in Germany, August 2009

2753 Daniel G. Arce, Dan Kovenock and Brian Roberson, Suicide Terrorism and the Weakest Link, August 2009

2754 Mario Larch and Wolfgang Lechthaler, Comparative Advantage and Skill-Specific Unemployment, August 2009

2755 Horst Raff and Nicolas Schmitt, Buyer Power in International Markets, August 2009

2756 Seppo Kari, Hanna Karikallio and Jukka Pirttilä, The Impact of Dividend Taxation on Dividends and Investment: New Evidence Based on a Natural Experiment, August 2009

2757 Mirco Tonin and Michael Vlassopoulos, Disentangling the Sources of Pro-social Behavior in the Workplace: A Field Experiment, August 2009

2758 Nicole Grunewald and Inmaculada Martínez-Zarzoso, Driving Factors of Carbon Dioxide Emissions and the Impact from Kyoto Protocol, August 2009 